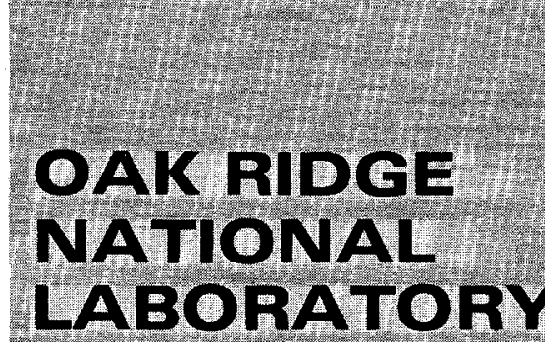

LockHEED HARTIN/4

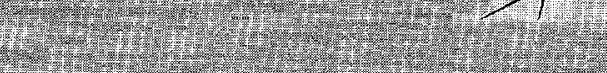

(1)

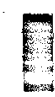

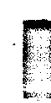

1

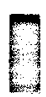

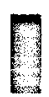

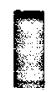

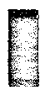

F

\%

]
WANAGED AMD OPERATED BY

LOCKHEEO MARTN ENERGY RESEAACH CORPORATION FOR THE UNIED STATES

DEPARTMENT OF ENERGY

\section{Improved Performance of the} Alkaline-Side CSEX Process for Cesium Extraction from Alkaline High-Level Waste Obtained by Characterization of the Effect of Surfactant Impurities

\author{
Laetitia H. Delmau \\ Gary J. Van Berkel \\ Peter V. Bonnesen \\ Bruce A. Moyer
}


This report has been reproduced from the best available copy.

Reports are available to the public from the following source.

National Technical Information Service

5285 Port Royal Road

Springfield, VA 22161

Telephone 703-605-6000 (1-800-553-6847)

TDD 703-487-4639

Fax 703-605-6900

E-mail orders @ ntis.fedworld.gov

Web site http://www.ntis.gov/ordering.htm

Reports are available to U.S. Department of Energy (DOE) employees, DOE contractors, Energy Technology Data Exchange (ETDE) representatives, and International Nuclear Information System (INIS) representatives from the following source.

Office of Scientific and Technical Information

P.O. Box 62

Oak Ridge, TN 37831

Telephone 423-576-8401

Fax 423-576-5728

E-mail reports@adonis.osti.gov

Web site http://www.osti.gov/products/sources.html

Reports produced after January 1, 1996, are generally available via the DOE information Bridge. Web site http://www.doe.gov/bridge 


\title{
IMPROVED PERFORMANCE OF THE ALKALINE-SIDE CSEX PROCESS FOR CESIUM EXTRACTION FROM ALKALINE HIGH-LEVEL WASTE OBTAINED BY CHARACTERIZATION OF THE EFFECT OF SURFACTANT IMPURITIES
}

\author{
Lætitia H. Delmau, Gary J. Van Berkel, Peter V. Bonnesen, and Bruce A. Moyer \\ Chemical and Analytical Sciences Division \\ Oak Ridge National Laboratory \\ P.O. Box 2008, Oak Ridge, Tennessee, 37831-6119 USA
}

The submitted manuscript has been authored by a contractor of the U.S. Government under contract No. DE-AC05-96OR22464. Accordingly, the U.S. Government retains a nonexclusive, royalty-free license to publish or reproduce the published form of this contribution, or allow others to do șo, for U.S. Government purposes.

This research was sponsored by the Efficient Separations and Processing Crosscutting Program, Office of Science and Technology, Office of Environmental Management, U. S. Department of Energy, under contract number DE-AC05-96OR22464 with Oak Ridge National Laboratory, managed by Lockheed Martin Energy Research Corp. 
Chemical and Analytical Sciences Division

\title{
IMPROVED PERFORMANCE OF THE ALKALINE-SIDE CSEX PROCESS FOR CESIUM EXTRACTION FROM ALKALINE HIGH-LEVEL WASTE OBTAINED BY CHARACTERIZATION OF THE EFFECT OF SURFACTANT IMPURITIES
}

\author{
Lætitia H. Delmau, Gary J. Van Berkel, Peter V. Bonnesen, and Bruce A. Moyer
}

Date Published-October 1999

\begin{abstract}
Prepared for the
U. S. Department of Energy, Office of Environmental Management, Office of Science and Technology, Efficient Separations and Processing Cross-Cutting Program
\end{abstract}

\author{
Prepared by the \\ OAK RIDGE NATIONAL LABORATORY \\ Oak Ridge, Tennessee 37831-6119 \\ managed by \\ LOCKHEED MARTIN ENERGY RESEARCH CORP. \\ for the \\ U. S. DEPARTMENT OF ENERGY \\ under contract DE-AC05-96OR22464
}




\section{CONTENTS}

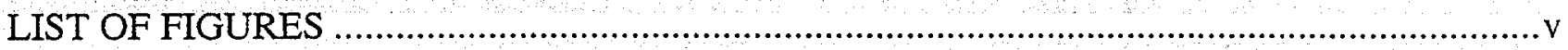

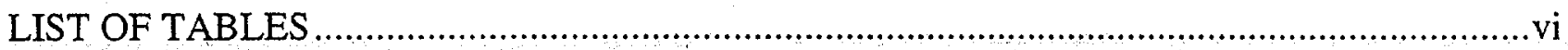

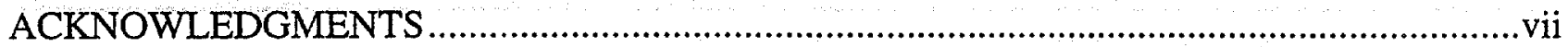

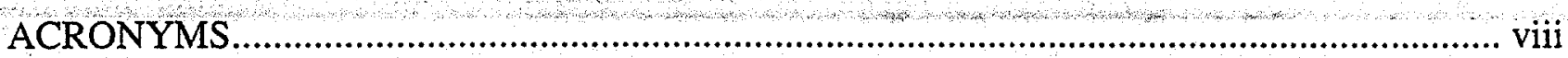

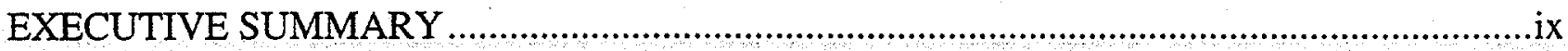

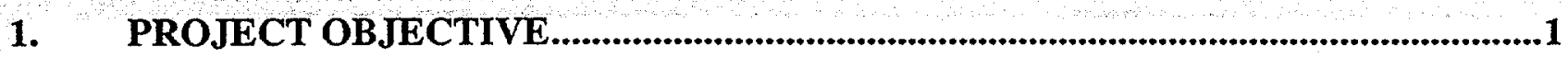

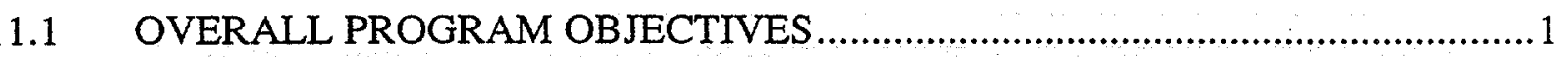

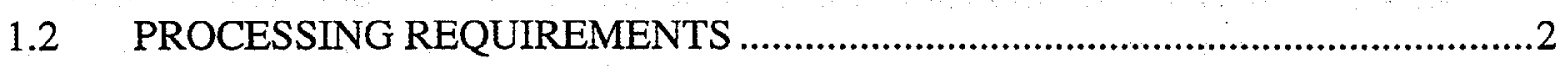

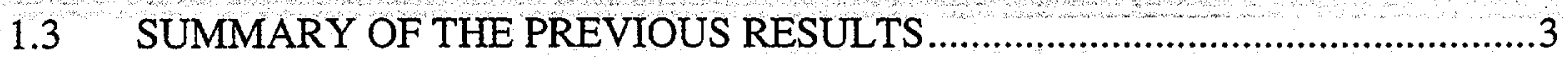

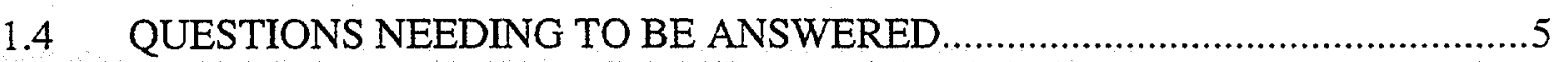

2. INITIAL TESTS

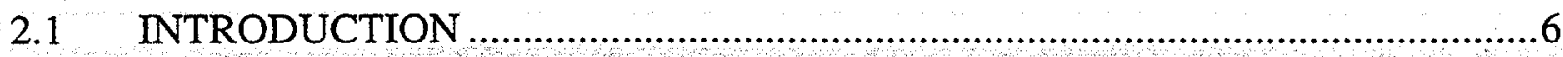

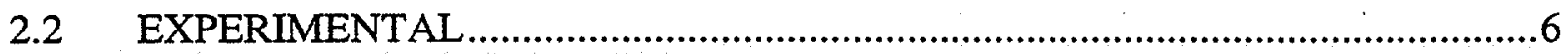

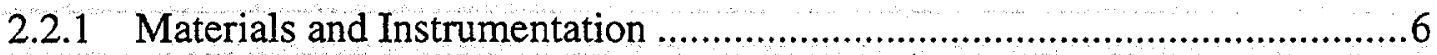

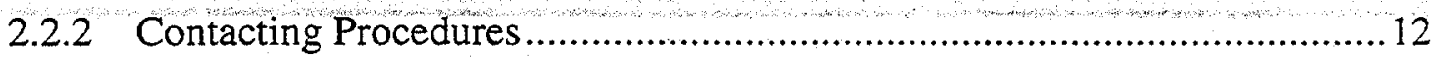

2.3 RESULTS AND DISCUSSION

2.3.1 Cesium Extraction from Simulants Prepared from ANL Salts ......................13

2.3.2 Influence of Physical Methods..............................................................14

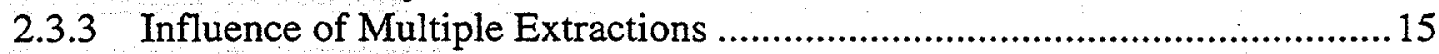

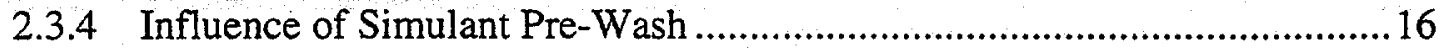

2.3.5 Influence of Trioctylamine Addition......................................................... 17

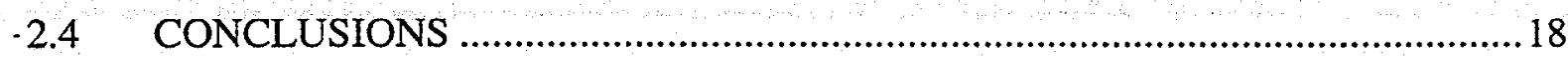




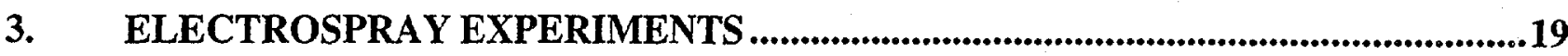

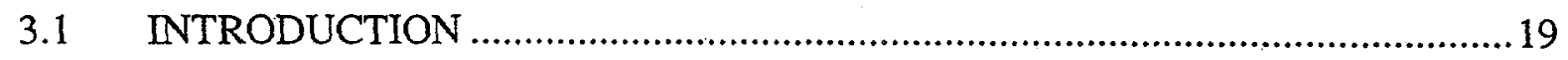

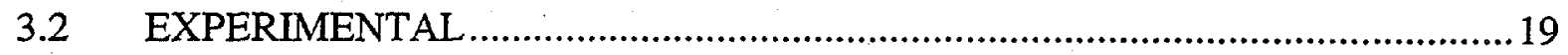

3.2.1 Materials and Contacting Procedure ....................................................19

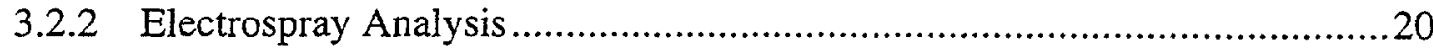

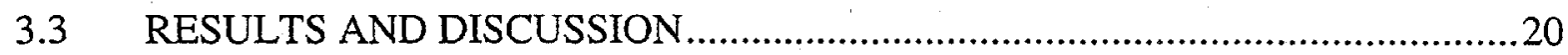

3.3.1 Overview of the Solvent at Different Stages ................................................20

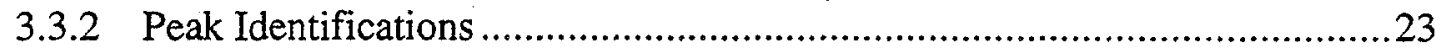

3.3.3 Comparison Between Simulants ........................................................28

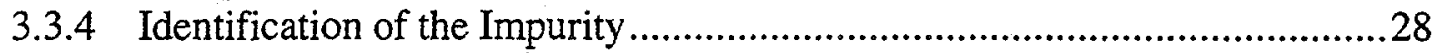

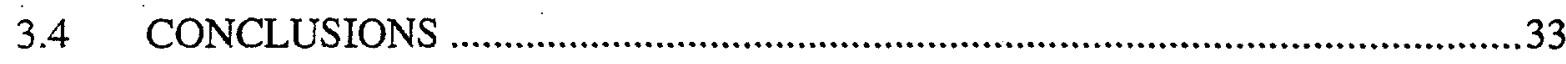

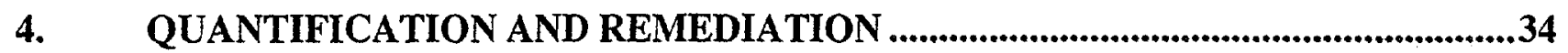

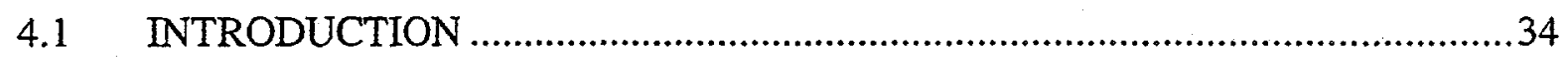

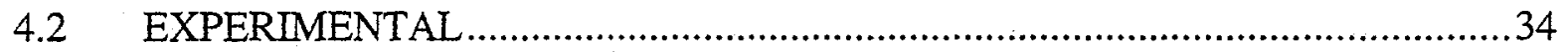

4.2.1 Materials and Preparation of Solutions ......................................................34

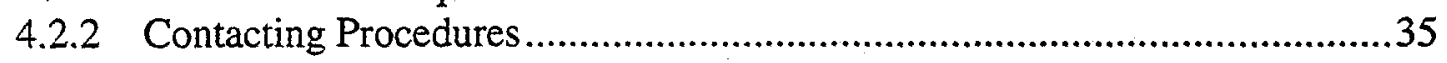

$4.3 \quad$ RESULTS AND DISCUSSION.........................................................................35

4.3.1 Effect of Dodecylsulfonate Anion on Cesium Extraction .............................35

4.3.2 Approximation of the Quantity of Sulfonate Present in ANL Simulant .......37

4.3.3 Remediation with Trioctylamine.................................................................38

4.4 CONCLUSIONS AND FURTHER DEVELOPMENTS …....................................38

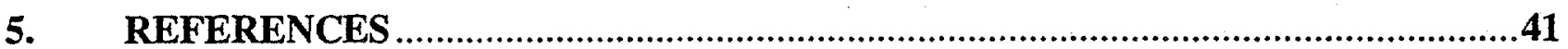




\section{LIST OF FIGURES}

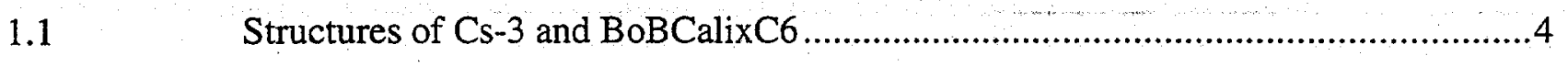

3.1 Cation-Mode Electrospray Spectrum of the Pristine Solvent …..............................

3.2 Cation-Mode Electrospray Spectrum of the Solvent Contacted 10 times with the

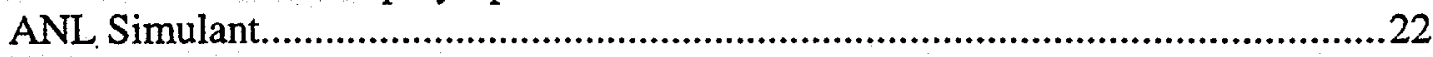

3.3 Anion-Mode Electrospray Spectrum of the Solvent Contacted 10 times with the ANL Simulant............................................................................................24

3.4 Anion-Mode Electrospray Spectrum of the Scrubbed Solvent .............................25

3.5 Anion-Mode Electrospray Spectrum of the Stripped Solvent ................................26

3.6 Structure of Cs-3 Condensation Product (Molecular Weight $642 \mathrm{~g} / \mathrm{mol}$ ) ...............27

3.7 Anion-Mode Electrospray Spectrum of the Solvent Contacted Twice with the

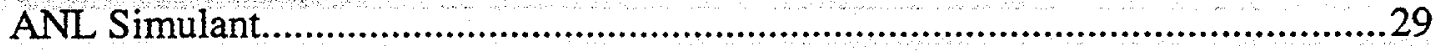

$3.8 \quad$ Anion-Mode Electrospray Spectrum of the Solvent Contacted Twice with the

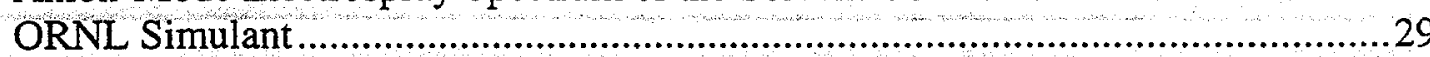

3.9 Anion-Mode Electrospray Spectrum Electrospray Spectrum of a 100,000-fold

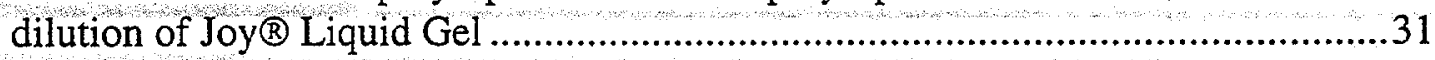

4.1 Effect of Dodecylsulfonate Anion on Cesium Distribution Ratios Under

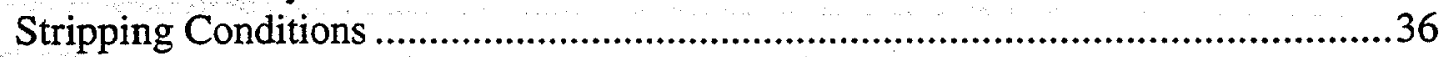

4.2 Effect of TOA on Cesium Extraction in the Presence of Dodecylsulfonate Anion in the Stripping Phase. 


\section{LIST OF TABLES}

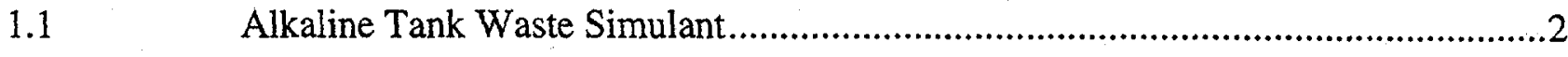

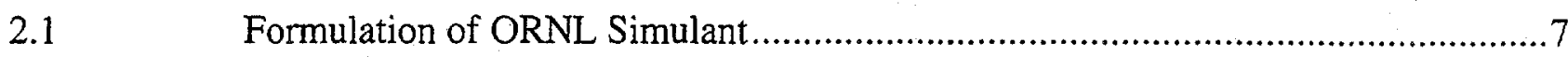

2.2 Formulation of ORNL Simulant Using ANL Salts and ORNL Water (ASOW-A) ...8

2.3 Formulation of ORNL Simulant Using ANL Salts and ANL Water (ASAW) ........9

2.4 Formulation of Simulant Containing Only One of the ANL Salts Prepared with

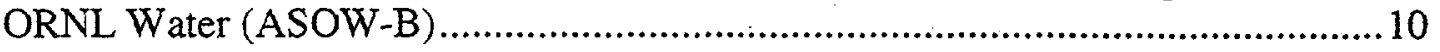

2.5 Formulation of Simulant Containing Only Four of the ANL Salts Prepared with

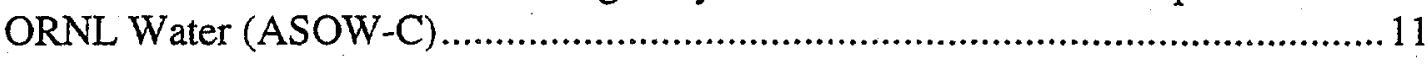

2.6 Comparison of Batch Results Obtained Using Different Simulants......................14

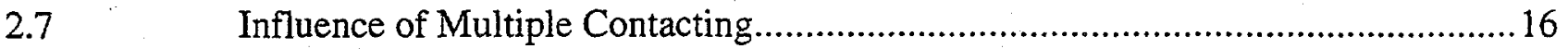

2.8 Influence of Simulant Washes with Different Solvents and Diluents ..................17

4.1 Cesium Distribution Ratios in Batch Tests Involving ORNL Simulant Containing

Controlled Amounts of Sulfonate ................................................................37 


\section{ACKNOWLEDGMENTS}

The authors would like to acknowledge the Efficient Separations and Processing (ESP) Crosscutting Program, Office of Science and Technology, Office of Environmental Management, U. S. Department of Energy, under contract number DE-AC05-960R22464 with Oak Ridge National Laboratory, managed by Lockheed Martin Energy Research Corp. for supporting the work presented in this report.

This research was also supported in part by an appointment (LHD) to the Oak Ridge National Laboratory Postdoctoral Research Associates Program administered jointly by the Oak Ridge Institute for Science and Education and Oak Ridge National Laboratory.

Finally, the authors wish to thank Jeffrey C. Bryan in the Chemical Separations Group of the ORNL Chemical and Analytical Sciences Division for many helpful discussions and for proofreading the manuscript. The authors would additionally like to thank our colleagues at Argonne National Laboratory (Clifford Conner and Ralph A. Leonard) for advice regarding engineering tests, and our colleagues at Savannah River (C.L. Crawford, F.F. Fondeur, R.A. Peterson, and T.L. White) for providing information on the process needs at the Savannah River Site. 


\section{ACRONYMS}

ANL

BoBCalix 6

CF

$\mathrm{Ci}$

Cs-3

CSEX

DF

USDOE

$D_{\mathrm{Cs}}$

ES-MS

ESP

Teflon ${ }^{\circledR}$ FEP

FW

HDDNS

HLW

ICP

LMER

$\mathrm{M} \Omega$

NMR

O/A

ORNL

PTFE

SRS

TBP

TCLP

TiOA

TOA
Argonne National Laboratory

Calix[4]arene-bis(tert-octylbenzo-crown-6)

Concentration Factor

Curie

1-(1,1,2,2-tetrafluoroethoxy)-3-(4-tert-octylphenoxy)-2-propanol

Cesium Solvent Extraction

Decontamination Factor

U.S. Department of Energy

Distribution ratio for cesium

Electrospray Mass Spectrometry

Efficient Separations Program

Fluorinated Ethylene Propylene

Formula Weight

Didodecylnaphthalene Sulfonic acid

High Level Waste

Inductively Coupled Plasma

Lockheed Martin Research Corporation

Mega Ohm

Nuclear Magnetic Resonance

Organic to Aqueous volume ratio

Oak Ridge National Laboratory

Polytetrafluoroethylene

Savannah River Site

Tributyl Phosphate

Toxic Characteristic Leaching Procedure

Triisooctylamine

Trioctylamine 


\section{EXECUTIVE SUMMARY}

Improved understanding and performance of the alkaline-side CSEX process has been obtained through the characterization of impurity effects that hinder complete stripping of cesium from the solvent. It is shown in this report that tests of the alkaline-side CSEX process conducted in the summer and fall of 1998 were complicated by the presence of common surfactant anions, undecyl-and dodecylsulfonate, as trace impurities in the two simulants tested. This conclusion was drawn from the results of a series of systematic extraction tests followed by a definitive identification by electrospray mass spectrometry (ES-MS). Based on this understanding, a straightforward preventative measure involving the addition of a lipophilic tertiary amine extractant at a small concentration to the solvent is proposed and demonstrated.

As part of the task "Fission Product Solvent Extraction" supported by the Efficient Separations and Processing Crosscutting Program within the USDOE Office of Environmental Management, the alkaline-side CSEX process has been developed for removal of radio-cesium $\left({ }^{137} \mathrm{Cs}\right)$ from alkaline high-level wastes stored in underground tanks at the Hanford Site and Savannah River Site (SRS). As described in a previous report, tests conducted in Fiscal Year 1998 generally demonstrated performance meeting the requirements for cesium removal from the waste to be treated at the SRS. However, discrepancies in stripping behavior were shown to arise from unidentified differences in the batches of waste simulant employed for testing. Various effects such as solvent impurities, kinetics, contacting method, and counting method were eliminated as possible causes of the observed discrepancies. Tests in Fiscal Year 1999 reported herein confirmed the earlier suspicion that the simulants contained lipophilic anionic impurities. Extraction tests demonstrated that the impurities could be concentrated in the solvent, and by ES-MS in the negative-ion mode it was possible to identify the harmful impurities as undecyl- and dodecylsulfonate. Subsequent tests with purchased sodium dodecylsulfonate confirmed that this surfactant could produce decreased stripping performance of the magnitude equivalent to that observed when using the simulant associated with the worse performance. With the identification of the impurity now settled, it is clear that poor stripping arises from ion-pair species in the solvent comprised of the cesium-extractant complex cation and the alkylsulfonate anion. Because the Gibbs energy of transfer of this anion and the complexation of the cesium cation by the extractant are both so favorable, the stripping of the 
cesium nitrate from the solvent is correspondingly unfavorable. Thus, once the cesium associated with nitrate ion in the solvent has been stripped, further stripping of the remaining cesium in the solvent becomes inefficient. A simple remedy is the addition of a lipophilic amine such as trioctylamine to the solvent. This well-known amine extractant, once proposed for reprocessing, remains neutral and essentially inert during extraction of the alkaline waste but converts to the trioctylammonium nitrate salt on scrubbing and stripping. This lipophilic salt remains in the organic phase and allows the final traces of cesium in the solvent to be stripped by supplying the alkylsulfonate impurity in the solvent with equivalent cationic charges. Further results regarding this and other improvements to the solvent system will be described elsewhere. 


\section{PROJECT OBJECTIVE}

\subsection{OVERALL PROGRAM OBJECTIVES}

The work reported herein was conducted as part of the task "Fission Product Solvent Extraction" supported by the Efficient Separations and Processing Crosscutting Program within the USDOE Office of Environmental Management. As the title implies, the task focused on the development of new solvent-extraction technology applicable to the removal of certain fission products, namely technetium-99 $\left({ }^{99} \mathrm{Tc}\right)$, cesium-137 $\left({ }^{137} \mathrm{Cs}\right)$, and strontium-90 $\left({ }^{90} \mathrm{Sr}\right)$, from waste. Efforts within this task have dealt mainly with high-level wastes stored in underground tanks at the Hanford Site, Savannah River Site (SRS) [1-3], and Idaho National Engineering and Environmental Laboratory (INEEL) [4].

Recently, the discovery of a new class of extractants, the calixarene-crowns (or calixcrowns) made it attractive for the first time to selectively remove cesium by solvent extraction from high-level wastes containing high salt concentrations. As originally discovered by European investigators [5-7], the calix-crowns have an unusually strong affinity for $\mathrm{Cs}^{+}$ions, with selectivity over $\mathrm{Na}^{+}$ions exceeding $10^{4}$. This discovery triggered an ORNL effort to adapt the new extractants to a solvent-extraction alternative to other technologies being examined at Hanford and the SRS, where the $\mathrm{Na} / \mathrm{Cs}$ mole ratio characteristic of high-salt tank wastes commonly lies in the range of $10^{4}$ to $10^{5}$. When the search for alternatives to the In-Tank Precipitation process at the SRS began in the spring of 1998, the development of the ORNL alkaline-side CSEX process was less than a year old and until then had been targeted at the Hanford wastes. Efforts in the spring and summer of 1998 at ORNL were subsequently devoted to further development and testing of this fledgling process to meet the specific needs at the SRS. The results of those tests through Sept. 30, 1998 have been described at length [1]. The present report addresses certain issues (see below) that were still outstanding at the time of the previous report. Further developments and improvements in the alkaline-side CSEX process are not included in the present report but will be reported in future journal publications $[8,9]$. 


\subsection{PROCESSING REQUIREMENTS}

The particular requirements to be met for removing ${ }^{137} \mathrm{Cs}$ from the liquid high-level waste stream at the SRS were summarized previously [1]. Two key requirements are for a decontamination factor (DF) of 40,000 and a concentration factor (CF) of 12.6. An average waste composition was specified, and a corresponding simulant recipe was prepared. The ionic composition of the simulant formulation used in this report is shown in Table 1.1.

Table 1.1. Alkaline Tank Waste Simulant ${ }^{\mathrm{a}}$

\begin{tabular}{ll}
\hline Species & Concentration $(\mathrm{M})$ \\
\hline $\mathrm{Na}^{+}$ & 6.52 \\
$\mathrm{~K}^{+}$ & 0.017 \\
$\mathrm{Cs}^{+}$ & $2.72 \times 10^{-4}$ \\
$\mathrm{Al}^{3+}$ & 0.440 \\
$\mathrm{OH}^{-}$(total) & 3.32 \\
$\mathrm{OH}^{-}$(free) & 1.54 \\
$\mathrm{NO}_{2}^{-}$ & 0.82 \\
$\mathrm{NO}_{3}^{-}$ & 2.70 \\
$\mathrm{~F}^{-}$ & 0.0502 \\
$\mathrm{Cl}^{-}$ & 0.100 \\
$\mathrm{SO}_{4}{ }^{2-}$ & 0.200 \\
$\mathrm{CO}_{3}{ }^{2-}$ & 0.230 \\
$\mathrm{CrO}_{4}{ }^{2-}$ & 0.015 \\
\hline
\end{tabular}

${ }^{2}$ Approximates likely feed for possible implementation of the alkaline-side CSEX process at the SRS. Listed are nominal concentrations; free hydroxide corresponds to the hydroxide concentration after stoichiometric reaction with $\mathrm{Al}^{3+}$ ion to give $\mathrm{Al}(\mathrm{OH})_{4}{ }^{-}$ion. The recipe for this simulant (labeled "SRS \#4") has been previously reported [10]. 


\subsection{SUMMARY OF THE PREVIOUS RESULTS}

A solvent-extraction system designed to selectively extract cesium from simulants of the wastes to be treated at the Savannah River Site was successfully demonstrated in batch tests at ORNL [1]. The system employs a solvent (Figure 1.1) comprised of a calixarene crown, bis(tertoctylbenzo-crown-6)calix[4]arene (BoBCalixC6), and a modifier, 1-(1,1,2,2-tetrafluoroethoxy)3-(4-tert-octylphenoxy)-2-propanol (Cs-3), dissolved in a branched aliphatic hydrocarbon diluent (Isoparß L). Several studies were performed on this system to test its properties regarding cesium extraction; minor-component extraction; partitioning of calixarene, modifier, and other minor organic species; and its integrity toward thermolytic and radiolytic conditions. Generally, acceptable results were obtained. The component concentrations were optimized to give both good extraction and stripping. Minor inorganic components were not extracted. The partitioning of the extractant and modifier to the aqueous phase was negligible. The scrub stages were sufficient to remove the extracted species other than cesium from the solvent. However, although the radiation tests performed at SRS showed only minor degradation [11], the results from the chemical stability tests [12] suggested that some improvement in the stability of the modifier in contact with the alkaline simulant would be desirable. The flowsheet calculated from the batch-test results by collaborators at Argonne National Laboratory (ANL) met requirements specified by workers at the SRS [13].

A significant and unexpected discrepancy emerged from comparisons of batch-test results obtained from different batches of the same simulant recipe. The batch tests involved the same extraction, scrub, and strip steps. Whereas the results on extraction and scrubbing were comparable, much less efficient stripping (factor of 4-5) was obtained at ANL. The hindered stripping was also reflected in centrifugal-contactor tests run in July and September 1998 at ANL. A study was then initiated at ORNL to address the origin of this discrepancy. The possible problem of kinetics was initially explored, since the residence time of the solutions in the centrifugal contactors was on the order of one second in the mixing zone. It was soon shown that the extraction kinetics were sufficiently fast for efficient use of centrifugal contactors [14]. We were also concerned with the possible incorporation of a chemical impurity, postulated to be a synthesis by-product or precursor to one of the components of the solvent. 


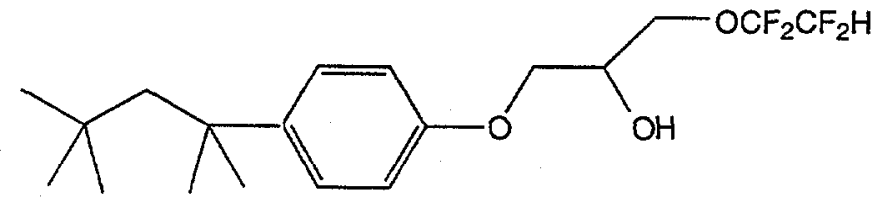

1-(1,1,2,2-tetrafluoroethoxy)-3-(4-tert-octylphenoxy)-2-propanol (Cs-3)

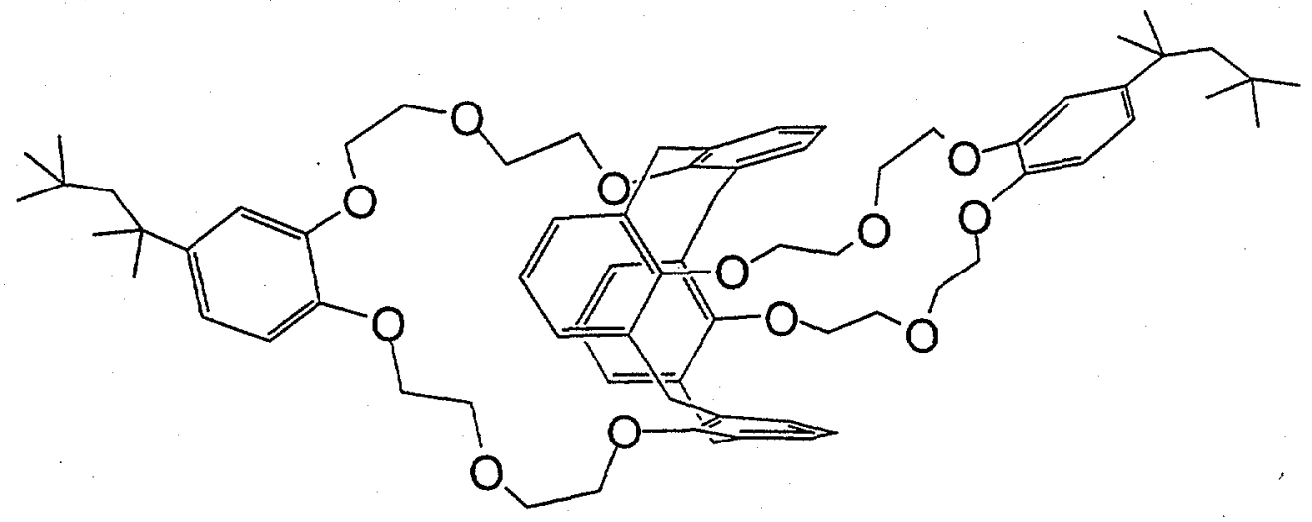

bis(tert-octyl benzo-crown-6)calix[4]arene (BoBCalixC6)

Figure 1.1. Structures of $\mathrm{Cs}-3$ and BoBCalixC6

Controlled addition of traces of 4-tert-octyl phenol (the starting material for the modifier synthesis) or tributylphosphate (that was detected in the recycled solvent after the contactor test of July 1998) to the pristine solvent produced no major consequences. Finally, several different procedures of simulant preparation were tested. They differed by the order of salt addition, by the type of container (glass vs. Teflon ${ }^{\circledR}$ FEP) used to prepare them, and by addition of a filtration pre-step. These differences also did not produce any change in results, nor did ICP analyses detect significant differences in the simulant compositions [10].

A clue to the origin of the discrepancy was provided when the stripping discrepancy was eliminated by the addition of an amine extractant (trioctylamine at ORNL and triisooctylamine at ANL) at low concentration to the solvent. This led to uniformly low cesium distribution ratios $\left(D_{\mathrm{Cs}}\right)$ on stripping [10]. Furthermore, addition of a cation-exchange agent (didodecylnaphthalene sulfonic acid, HDDNS) to the system had the opposite effect and increased the $D_{\mathrm{Cs}}$ values dramatically. These observations tended to implicate an anionic impurity unique to the tests conducted at ANL. 


\subsection{QUESTIONS NEEDING TO BE ANSWERED}

At the conclusion of the ORNL TM report published in December 1998 [10], it was suggested that the discrepancy in stripping performance came from a chemical difference in the two simulants prepared at ORNL and ANL. Questions concerned a) what was different about the ANL and ORNL simulants, b) whether there was an inorganic or organic impurity in the ANL simulants, c) whether the same material was also present in the ORNL simulants, and d) whether the ORNL simulants actually contained something else to begin with that improved stripping. The purpose of this report is to answer the questions and, if possible, provide a reasonable explanation for how chemical differences in the simulants could impact stripping performance. Although the hypothesis of an anionic impurity in the simulant was mentioned [10], it had not yet been confirmed nor had its origin been determined. However, it was the only obvious explanation for the results obtained at that time. This report presents extensive studies confirming this hypothesis, with consideration of other reasonable explanations. 


\section{INITIAL TESTS}

\section{$2.1 \quad$ INTRODUCTION}

The question to be answered in this chapter concerns the origin of the discrepancy in the stripping cesium distribution ratios obtained during extraction, scrubbing, and stripping operations using different batches of simulants prepared according to the same recipe. All potential sources of the discrepancy were carefully checked. Most of the comparative studies were performed at ORNL and involved the use of chemical reagents from both ORNL and ANL, as well as simulant prepared at ANL. Because poor stripping had been obtained at ANL using the solvent prepared at ORNL, it was rational to think that the cause of the discrepancy was introduced by the simulant. Previous results showed that the preparation of the simulant according to the ANL procedure using ORNL materials did not introduce any change. Initially, we used a simulant prepared at ORNL from selected salt samples received from ANL, then compared the cesium distribution ratios with those from the simulant prepared at ANL. We also tested some ANL-prepared simulant at ORNL, which allowed comparison of the physical methods of stirring, centrifuging, and $\gamma$-counting. Finally, the effect of adding trioctylamine to the solvent was assessed. The results demonstrated that the impurity was likely anionic and lipophilic, and did not originate from the selected salts or water used at ANL.

\subsection{EXPERIMENTAL}

\subsubsection{Materials and Instrumentation}

Reagents. All salts and solvents were reagent grade and were used as received. The origin of the salts can be found in the tables describing the simulant tests (Tables 2.1 to 2.5). Distilled, deionized water was obtained from a Barnstead Nanopure filtering system (resistivity $18 \mathrm{M} \Omega$ ) and was used to prepare all aqueous solutions, including the simulants. Nitric acid was Ultrex II grade (J.T. Baker). Dilute nitric acid solutions were prepared by volumetric dilution, and the $\mathrm{pH}$ was checked using an Orion ${ }^{\circledR}$ Model $230 \mathrm{~A} \mathrm{pH}$ meter with an Orion ${ }^{\circledR}$ Ross $8103 \mathrm{pH}$ 


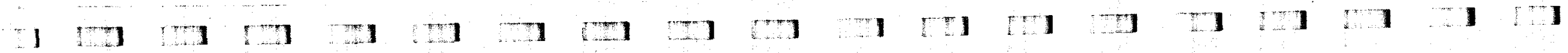

Table 2.1. Formulation of ORNL Simulant

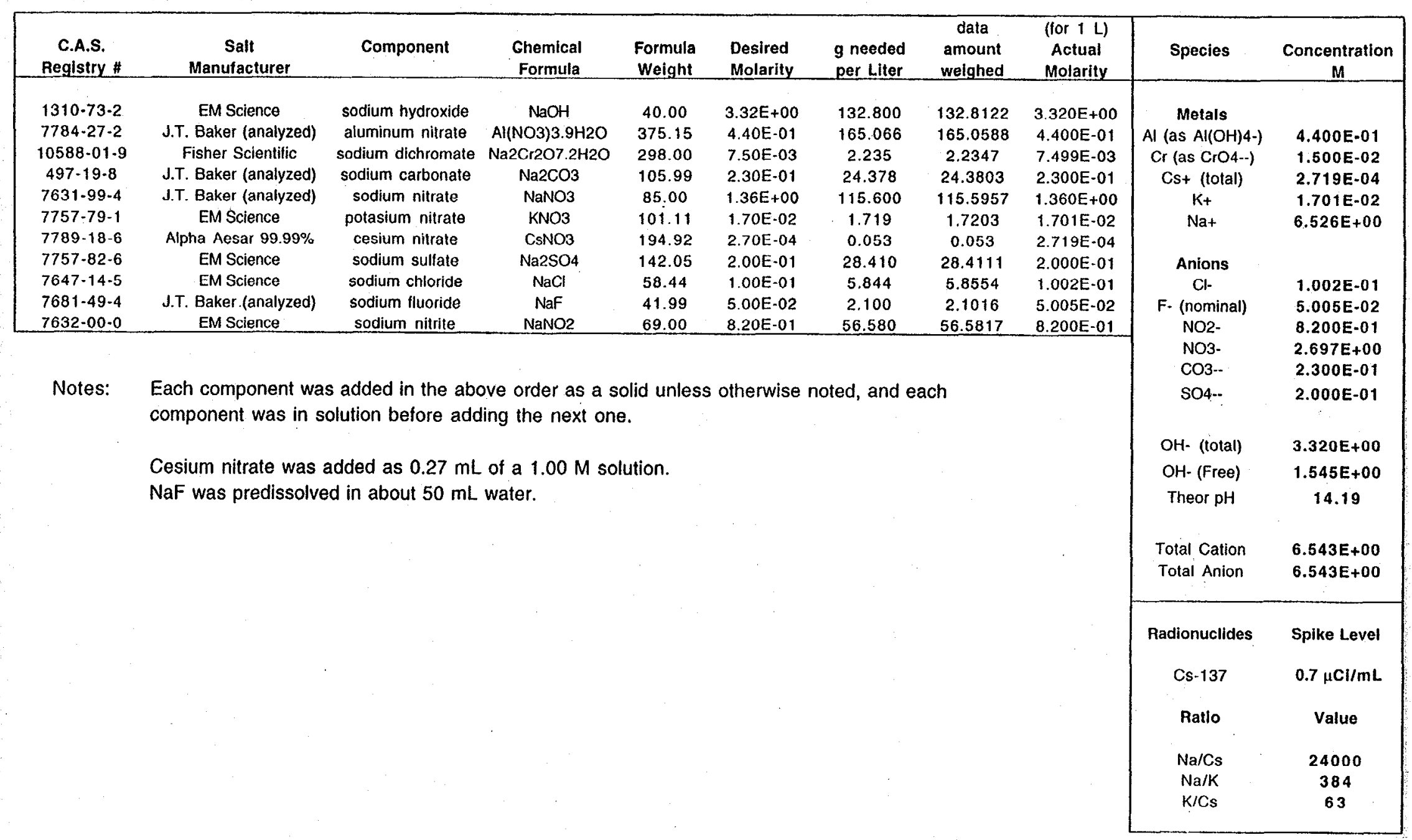


Table 2.2. Formulation of ORNL Simulant Using ANL Salts and ORNL Water (ASOW-A)

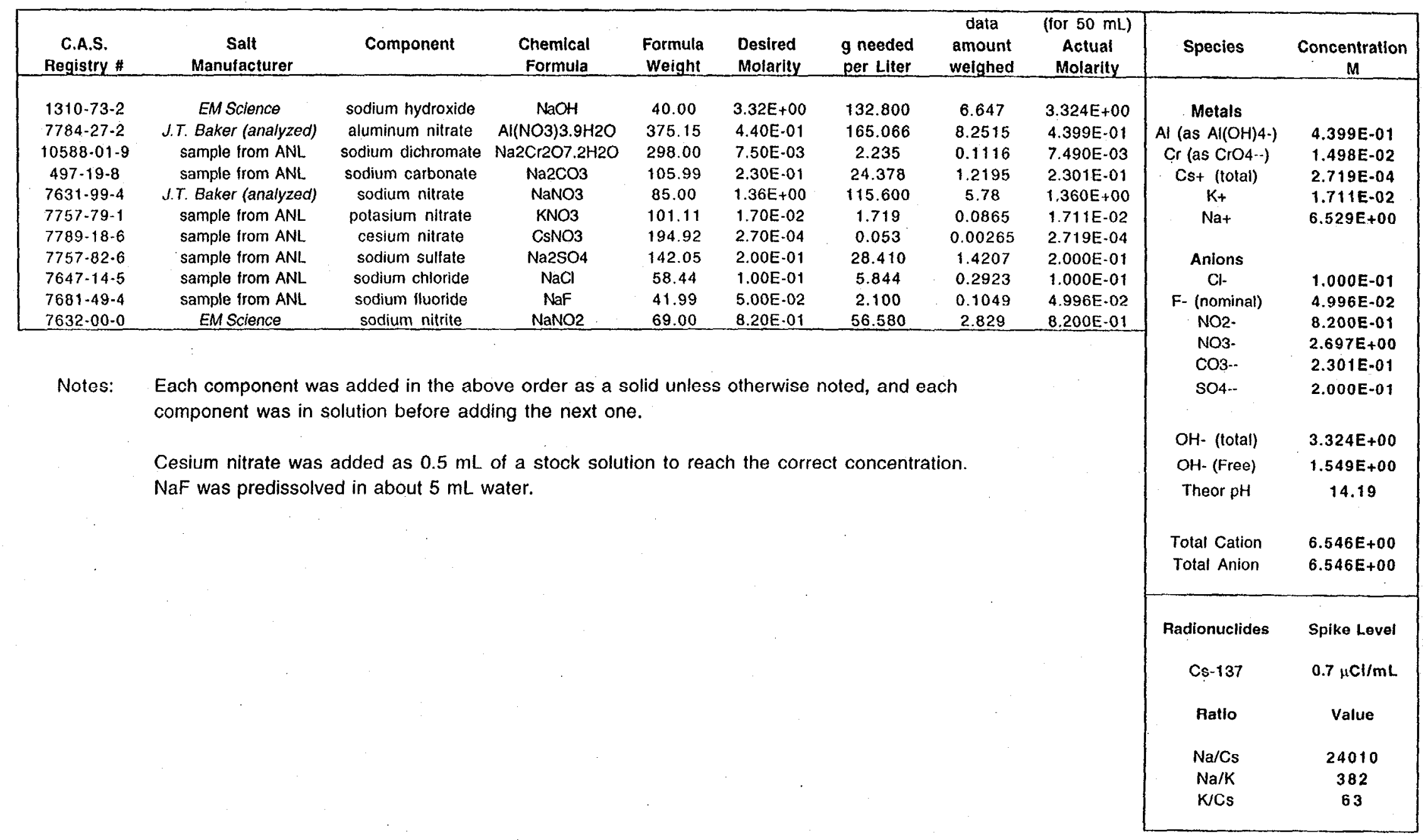




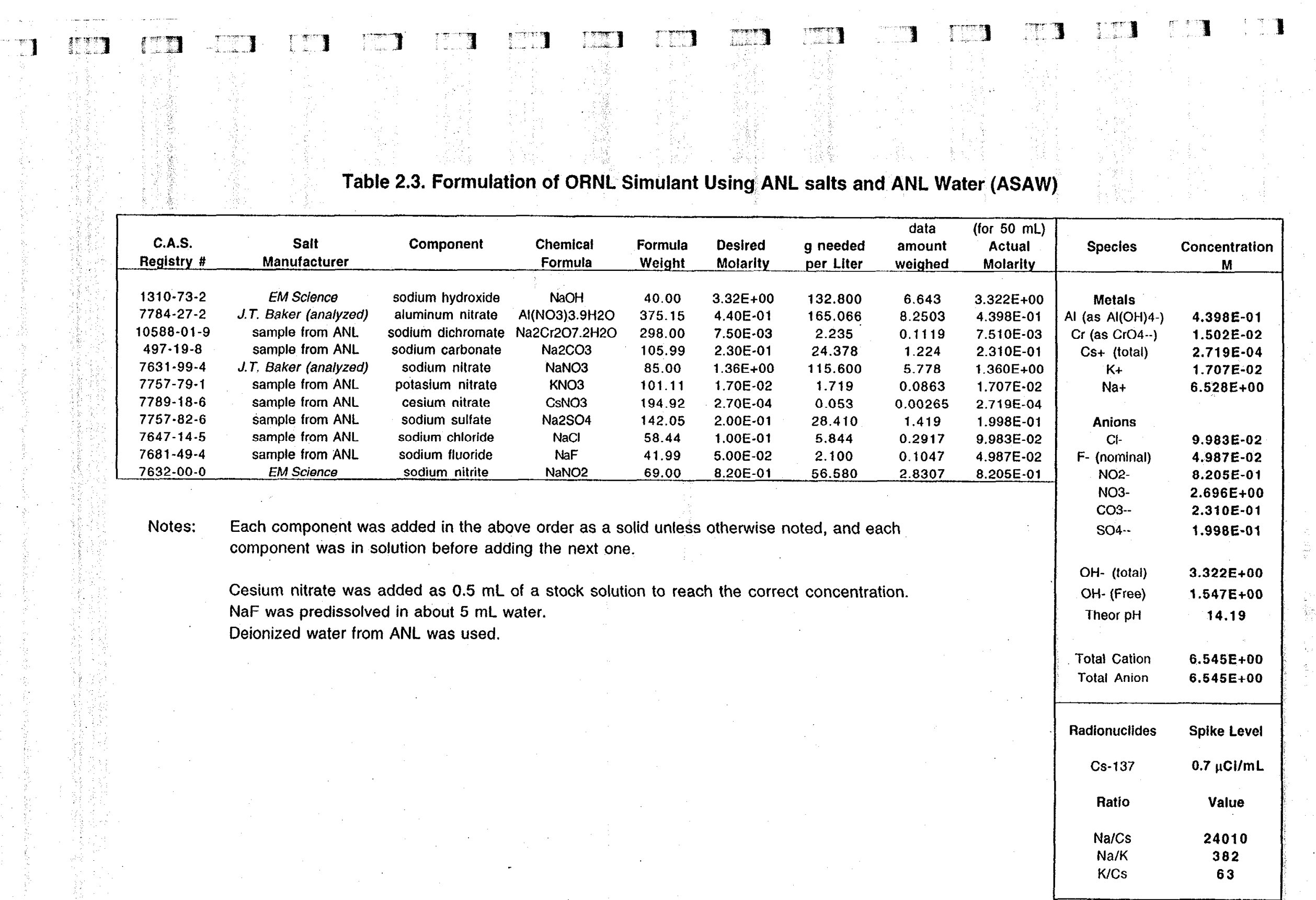


Table 2.4. Formulation of Simulant Containing Only One of the ANL Salts Prepared With ORNL Water (ASOW-B)

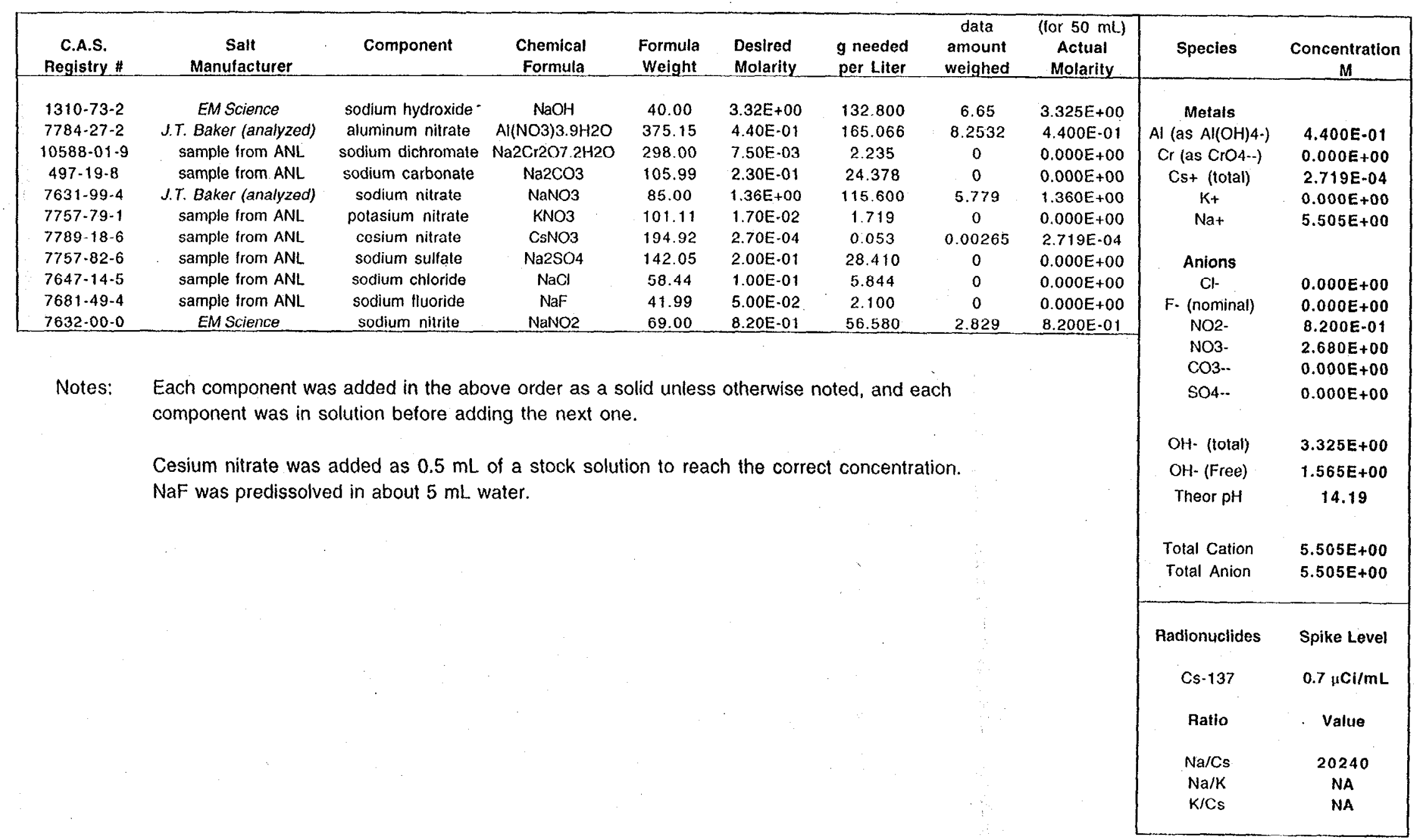




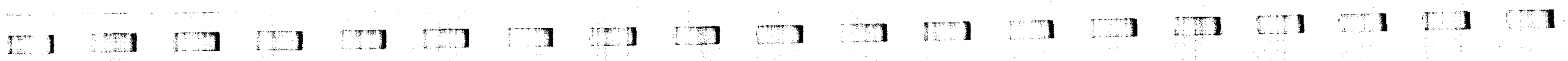

Table 2.5. Formulation of Simulant Containing Only Four of the ANL Salts Prepared With ORNL Water (ASOW-C)

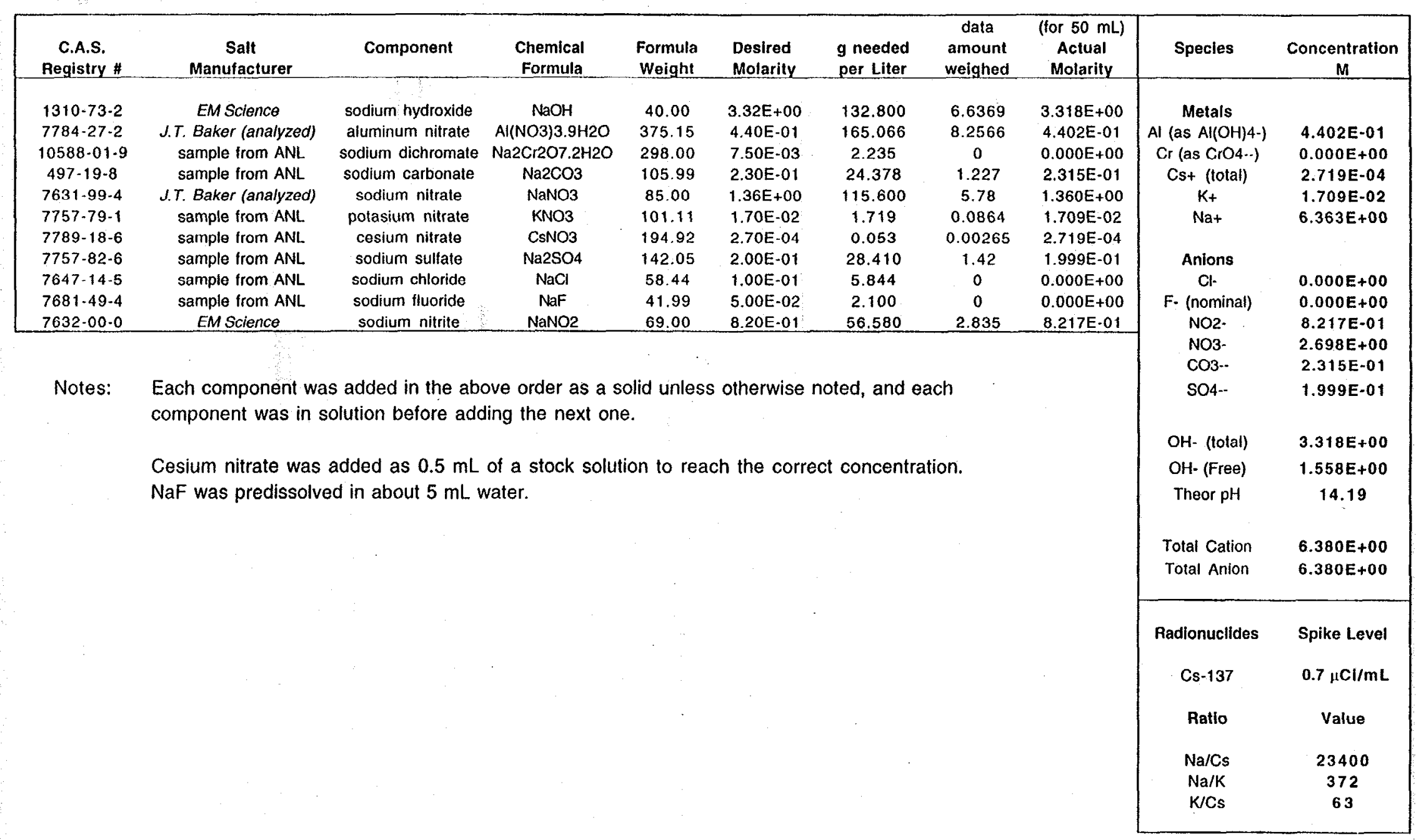


electrode. The meter was calibrated (two-point) prior to use. Isopar ${ }^{\circledR} \mathrm{L}$ isoparaffinic diluent (lot\# 0306 10967) was obtained from Exxon Chemical Company, Houston, Texas. The BoBCalixC6 (lot\# IBC $980731 \mathrm{KC}-428$ ) was obtained from IBC Advanced Technologies (American Fork, UT).

Cesium-137 Radiotracers. The ${ }^{137} \mathrm{Cs}$ radiotracer used for spiking the waste simulants was obtained as ${ }^{137} \mathrm{CsCl}$ in $1 \mathrm{M} \mathrm{HCl}$ from Amersham (Arlington Heights, $I L$ ) and was used as received. For experiments where it was necessary to have an acid-free source of ${ }^{137} \mathrm{CsNO}_{3}$, (as for example experiments aimed at examining the stripping mechanism) a portion of the ${ }^{137} \mathrm{CsCl}$ in $1 \mathrm{M} \mathrm{HCl}$ was converted to ${ }^{137} \mathrm{CsNO}_{3}$ in water following a procedure described elsewhere [15].

Gamma Counting of Cesium. The cesium activity in the samples was determined by standard gamma( $\gamma$ )-counting techniques using a Packard ${ }^{\circledR}$ Cobra Quantum Model 5003 gamma counter equipped with a 3 " $\mathrm{NaI}(\mathrm{Tl})$ crystal through-hole type detector. A counting window of

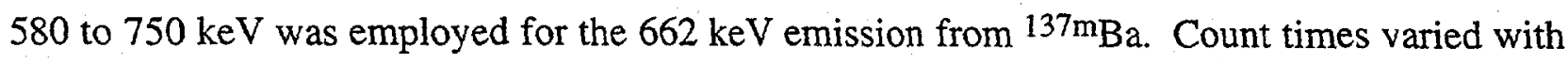
the activity of the sample but were generally long enough to ensure that a total of 1000 total counts had been collected. A decay time (following separation of the aqueous and organic phases) of at least $1 \mathrm{hr}$ was employed to ensure that secular equilibrium had been achieved

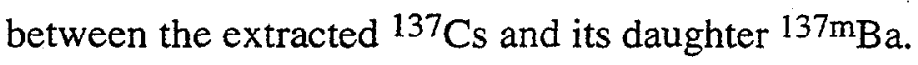

\subsubsection{Contacting Procedures}

The experiments conducted in this report involving cesium radiotracers can be divided into two categories: the "forward" experiments and the sequential contacting experiments. For both categories of experiments, extraction was carried out by rotating the tubes end-over-end at $50-60 \mathrm{RPM}$ for 30 minutes at $25 \pm 0.2{ }^{\circ} \mathrm{C}$ using a Glass-Col ${ }^{\otimes}$ laboratory rotator and centrifuging (Sanyo MSE Mistral 2000R) for 3 minutes at $4000 \mathrm{rpm}$ at $25^{\circ} \mathrm{C}$. Aliquots of each phase were analyzed for ${ }^{137} \mathrm{Cs}$ activity. 


\section{Cesium extraction "forward" experiments}

These experiments involved the extraction of cesium from an aqueous phase containing only nitric acid and cesium nitrate by pristine solvent. They were designed to probe the system behavior upon stripping without performing the prerequisite extraction and scrubbing steps. However, it was only a first approximation, since the starting points were different (cesium in the aqueous phase vs. cesium in the organic phase) and since the solvent, unlike for the sequential batch tests, did not contain any other metals or acid carried-over from the scrub stages. Unless noted, experiments were performed by contacting $1.5-\mathrm{mL}$ portions of organic and aqueous phases together in polypropylene tubes (sealed with screw caps equipped with polyethylene inner liners). The aqueous phases were spiked with ${ }^{137} \mathrm{Cs}$ tracer before contact.

\section{Sequential contacting experiments}

These batch tests comprised a succession of steps designed to mimic the different stages in an extraction, scrub, and strip cycle. Consecutive contacts consisted of:

- extractions of cesium from a simulant of the SRS high-level waste,

- scrubs of the organic phase with $50 \mathrm{mM}$ nitric acid to remove the other cations extracted during the cesium extraction stages (such as sodium, potassium, and aluminum),

- strips of the organic phase with a mixture of $0.5 \mathrm{mM}$ nitric acid and $0.1 \mathrm{mM}$ cesium nitrate in order to remove all the activity and concentrate the radio-cesium in one clean effluent stream.

After each step, an aliquot was subsampled from both phases for ${ }^{137} \mathrm{Cs}$ activity analyses, and a given volume of solvent was transferred into a new vial for the next step. The volume ratio of the two phases was varied, as will be described below for each experiment.

\subsection{RESULTS AND DISCUSSION}

\subsubsection{Cesium Extraction from Simulants Prepared from ANL Salts}

Samples of all the minor simulant component salts and of deionized water were sent to ORNL by the team at ANL. These salts and the water were used to prepare simulants to check whether the impurity originated in one of these salts or from the water. ANL samples of the 
major salts employed in the preparation of the simulant [e.g., $\mathrm{NaOH}, \mathrm{NaNO}_{2}, \mathrm{NaNO}_{3}$, and $\mathrm{Al}\left(\mathrm{NO}_{3}\right)_{3}$ ] were not used, as bottles from different lots were consumed in ANL simulant preparation over several months (therefore decreasing the probability of having the same impurity) without loss of reproducibility. Table 2.6 presents all the results obtained with this simulant and allows comparison to the ORNL simulant.

Table 2.6. Comparison of Batch Results Obtained Using Different Simulants ${ }^{a}$

\begin{tabular}{lcccccc}
\hline \multirow{2}{*}{ Operation } & \multicolumn{6}{c}{$D_{\mathrm{Cs}}$} \\
\cline { 2 - 7 } & ORNL & ANL & ASOW-A & ASOW-B & ASOW-C & ASAW \\
\hline $1^{\text {st }}$ Extraction & 11.21 & 17.03 & 11.43 & 15.55 & 11.74 & 11.84 \\
$2^{\text {nd }}$ Extraction & 11.20 & 16.73 & 10.86 & 15.09 & 11.06 & 11.11 \\
Scrub & 0.701 & 0.809 & 0.703 & 0.699 & 0.707 & 0.756 \\
$1^{\text {st }}$ Strip & 0.038 & 0.135 & 0.042 & 0.034 & 0.041 & 0.041 \\
$2^{\text {nd }}$ Strip & 0.073 & 0.264 & 0.087 & 0.060 & 0.026 & 0.077 \\
$3^{\text {rd }}$ Strip & 0.077 & 0.226 & 0.078 & 0.064 & 0.099 & 0.072 \\
\hline
\end{tabular}

a See description of simulants in Tables 2.1 to 2.5. Organic phase: BoBCalixC6 $0.01 \mathrm{M}+$ modifier Cs-3 $0.2 \mathrm{M}$ in Isopar@ L. Aqueous phases: fresh simulant for each extraction, $50 \mathrm{mM}$ nitric acid for the scrubs, $0.5 \mathrm{mM}$ nitric acid $+0.1 \mathrm{mM}$ cesium nitrate for the strips. Contacts were run at $25^{\circ} \mathrm{C}$ and $\mathrm{O} / \mathrm{A}=1$. All data were obtained from measurements at ORNL.

It may be seen from the data in Table 2.6 that stripping is approximately 4-fold less efficient with the simulant received from ANL. However, stripping was relatively unaffected when the selected ANL salts or deionized water were used. Thus, the putative impurity leading to the previously observed discrepancy did not originate from the water or the selected ANL simulant salts.

\subsubsection{Influence of Physical Methods}

The influence of physical methods involved in contacting and counting was checked 
indirectly and ruled out as the source of stripping discrepancies [1]. Several experiments performed at ANL were repeated at ORNL using samples of solvent and simulant received from ANL. Thus, the only differences lay in the physical methods adopted to perform the cesium extraction experiments. The ANL procedure involved immersing the samples in a $25^{\circ} \mathrm{C}$ water bath, vortexing the samples for a few minutes, immersing the samples again in a $25^{\circ} \mathrm{C}$ water bath, centrifuging, and then separating and counting the two phases $\gamma$-counting in HPGE welltype detector. The counting technique by $\beta$-liquid scintillation was also used on a few samples to confirm the accuracy of the $\gamma$-counting method. At ORNL, the procedure involved rotating the tubes end-over-end for at least half an hour at $25^{\circ} \mathrm{C}$, centrifuging, and then separating and counting the two phases by $\gamma$-counting (details are given in the Experimental Section). Two observations were made:

- ANL and ORNL results agreed; therefore, the methods used to run the experiments were adequate and equivalent in results.

- Poor stripping results were obtained at ORNL with ANL simulant (Table 2.6).

\subsubsection{Influence of Multiple Extractions}

Two experiments were conducted to test the possibility of impurity build-up in the organic phase upon extraction. One experiment was performed using the ANL simulant, the other using the ORNL simulant. Fresh solvent was contacted at total of five times with the simulant (four times with cold simulant, the fifth time with simulant containing ${ }^{137} \mathrm{Cs}$ tracer), scrubbed once, and then stripped three times. The results are presented in Table 2.7.

The effect on the stripping efficiency was dramatic. An increase of stripping cesium distribution values may be seen for both ANL and ORNL simulants, strongly suggesting some impurity build-up in both cases. However, the decrease in stripping efficiency (increase of $D_{\mathrm{Cs}}$ ) was less dramatic for the ORNL simulant. The results suggest that, in each case, an impurity must be highly extractable and remains so through scrubbing and stripping steps. 
Table 2.7. Influence of Multiple Contacting ${ }^{a}$

\begin{tabular}{lcccc}
\hline \multirow{2}{*}{ Operation } & \multicolumn{4}{c}{$D_{\mathrm{Cs}}$} \\
\cline { 2 - 5 } & ORNL & $\begin{array}{c}\text { ORNL } \\
\text { (4 pre-equilibrations) }^{b}\end{array}$ & ANL & $\begin{array}{c}\text { ANL } \\
\text { (4 pre-equilibrations) }^{b}\end{array}$ \\
\hline $1^{\text {st }}$ Extraction & 11.21 & $b$ & 17.03 & $b$ \\
$2^{\text {nd }}$ Extraction & 11.20 & 9.42 & 16.73 & 14.44 \\
Scrub & 0.701 & 0.695 & 0.809 & 0.796 \\
$1^{\text {st }}$ Strip & 0.038 & 0.045 & 0.135 & 0.214 \\
$2^{\text {nd }}$ Strip & 0.073 & 0.119 & 0.264 & $\mathbf{0 . 7 7 5}$ \\
$3^{\text {rd }}$ Strip & 0.077 & 0.118 & 0.226 & $\mathbf{0 . 7 3 9}$ \\
\hline
\end{tabular}

a Organic phase: BoBCalixC6 $0.01 \mathrm{M}+$ modifier Cs-3 $0.2 \mathrm{M}$ in Isopar® L. Aqueous phases: ANL or ORNL simulants for the extractions, $50 \mathrm{mM}$ nitric acid for the scrub, $0.5 \mathrm{mM}$ nitric acid $+0.1 \mathrm{mM}$ cesium nitrate for the strips. Contacts were run at $25^{\circ} \mathrm{C}$ and $\mathrm{O} / \mathrm{A}=1$. ${ }^{b}$ The pre-equilibrations were carried out using the same aqueous simulant, but without ${ }^{137} \mathrm{Cs}$ tracer. The fifth contact also contained no tracer, and the value of $D_{\mathrm{Cs}}$ was not determined, as indicated in the fist row of the data shown.

\subsubsection{Influence of Simulant Pre-Wash}

Having established that the presence of impurities in the simulants was likely, a series of experiments was conducted to determine whether portions of impurities could be removed by washing the simulant with different types of diluents or solvents (Table 2.8). Washes with only Isopar ${ }^{\circledR} L$ or hexane did not change the stripping results, which suggests that although the putative impurity is lipophilic, its extraction requires polar solvent components. Accordingly, when Cs-3 modifier is added to the diluent (at a concentration equal to the one used in the solvent containing the calixarene), there is a fair improvement in the stripping values. This indicates that some of the impurity was removed from the simulant during the washes, consistent with it being either a neutral compound or a lipophilic salt. 
Table 2.8. Influence of Simulant Washes with Different Solvents and Diluents ${ }^{a}$

\begin{tabular}{lccccc}
\hline Operation & $\begin{array}{c}\text { ANL } \\
\text { simulant }\end{array}$ & $\begin{array}{c}\text { Washed } \\
\text { with } \\
\text { Isopar® } \\
\text { five times }\end{array}$ & $\begin{array}{c}\text { Washed with } \\
\text { Isopar® L+ } \\
\text { modifier Cs-3 } \\
\text { five times }\end{array}$ & $\begin{array}{c}\text { Washed with } \\
\text { hexane five } \\
\text { times }\end{array}$ & $\begin{array}{c}\text { Washed with } \\
\text { hexane+ } \\
\text { modifier Cs-3 }\end{array}$ \\
\hline $1^{\text {st }}$ Extraction & 17.03 & 17.04 & 17.64 & b & five times \\
\hline $2^{\text {nd }}$ Extraction & 16.73 & 16.60 & 16.61 & 17.33 & 16.69 \\
Scrub & 0.809 & 0.840 & 0.771 & 0.968 & 16.54 \\
$1^{\text {st }}$ Strip & 0.135 & 0.136 & 0.040 & 0.162 & 0.765 \\
$2^{\text {nd }}$ Strip & 0.264 & 0.254 & 0.064 & 0.239 & 0.047 \\
$3^{\text {rd }}$ Strip & 0.226 & 0.202 & 0.057 & 0.211 & 0.084 \\
\hline
\end{tabular}

$a$ Organic phase: BoBCalixC6 $0.01 \mathrm{M}+$ modifier Cs-3 $0.2 \mathrm{M}$ in Isopar ${ }^{\circ} \mathrm{L}$. Aqueous phases: ANL simulant (type of wash, see in the table) for the extractions, $50 \mathrm{mM}$ nitric acid for the scrub, $0.5 \mathrm{mM}$ nitric acid $+0.1 \mathrm{mM}$ cesium nitrate for the strips. Contacts were run at $25^{\circ} \mathrm{C}$ and $\mathrm{O} / \mathrm{A}=1$. $^{\mathrm{b}}$ The pre-equilibration was carried out using the same aqueous simulant, but without ${ }^{137} \mathrm{Cs}$ tracer.

\subsubsection{Influence of Trioctylamine Addition}

Results from a previous series of experiments run at ORNL involving the addition of trioctylamine (TOA) to the solvent provided support to the conclusions mentioned in the preceding subsection [1]. Trioctylamine converts to the large lipophilic trioctylammonium cation when in contact with the acid scrub and strip stages. If the hypothesis that a lipophilic anion is being extracted into the organic solvent is correct, then a large lipophilic cation added to the solvent in excess concentration would be expected to nullify the anion's effect. That is, all of the cesium present in the solvent as the cesium-calixarene complex can be stripped as cesium nitrate, since the alkylammonium nitrate salt supplies the needed nitrate co-anion, and the negative equivalents of lipophilic anion in the solvent are compensated by the positive equivalents of the ammonium cation. Data collected at both ANL and ORNL demonstrated a dramatic improvement in stripping upon addition of trioctylamine to the solvent [1]. At ANL, $0.1 \mathrm{mM}$ triisooctylamine (TiOA) gave good values of $D_{\mathrm{Cs}}$ in the range of $0.036-0.04$ on stripping. 
Using a simulant prepared at ANL, it was shown at ORNL that the addition of $0.1 \mathrm{mM}$ TOA to the solvent after the third strip decreased $D_{\mathrm{Cs}}$ from 0.26 to 0.024 .

\subsection{CONCLUSIONS}

The following observations were made earlier [1]:

- Cesium distribution ratios on stripping the solvent after contact with the ANL simulant were significantly higher than after contact with the ORNL simulant. This observation held true regardless of

a. where the experiments were performed

b. where fresh solvent was prepared

c. where the minor salts or water originated.

- Solvent that had contacted ANL simulant displayed decreased strippability, even after undergoing scrubbing and stripping steps. However, moderate improvement in stripping of this used solvent could be effected by multiple washings with dilute $\mathrm{NaOH}$ solutions [10].

The following observations could be made from the present experiments:

- Repeated contacts of the solvent with either the ORNL or the ANL simulant decreases the stripping performance, though the effect is more pronounced with the ANL simulant.

- Precontacting the ANL simulant with a solvent containing modifier and diluent improves the stripping performance.

From these observations, one may conclude that harmful chemical impurities in both simulants are the likely cause of the irreproducibility in stripping performance. The preparation of fresh solvent, the procedures used for phase-contacting, and the instrumental methods of analysis can be ruled out. The putative impurities must be lipophilic, and they are likely anionic. In the ANL simulant, the impurities are either the same but in higher concentrations, or are different but more deleterious to stripping, as compared with the ORNL simulant. 


\section{ELECTROSPRAY EXPERIMENTS}

\subsection{INTRODUCTION}

With the establishment that the irreproducibility in stripping performance was likely caused by an anionic impurity that was co-extracted with cesium, it was desirable to subject the extraction solvent to direct analysis for the impurity. A sensitive technique for this purpose is electrospray mass spectrometry (ES-MS). The softness of the technique allows dissociation of the ion-paired species present in the solution without breaking the structures of the ions. In addition, charged complexes of ions with neutral molecules can be detected. Depending on the chosen mode, either cations or anions can be observed. In view of the evidence implicating anionic impurities, the solvent was taken through extraction, scrub, and strip steps and analyzed at each step by ES-MS in the negative ion mode.

\subsection{EXPERIMENTAL}

\subsubsection{Materials and Contacting Procedure}

The experiments were performed using the solvent and the two simulants from ANL and ORNL (Table 2.1). A solution of a commercially-available dish detergent on hand at ORNL (Joy ${ }^{\circledR}$ liquid gel) in water was also analyzed.

For the first experiment, the pristine solvent was contacted 10 times with the ANL simulant $(\mathrm{O} / \mathrm{A}$ ratio $=0.2)$. After each extraction, the aqueous phase was removed and replaced by fresh simulant. After the $10^{\text {th }}$ extraction, an aliquot of the solvent was reserved $(2 \mathrm{~mL})$, and the remainder contacted once with an equal volume of scrub solution (nitric acid $50 \mathrm{mM}$ ). Again, an aliquot of the solvent was saved, and the remainder contacted once with an equal volume of strip solution (nitric acid $0.5 \mathrm{mM}$ and cesium nitrate $0.1 \mathrm{mM}$ ). For the second experiment, the pristine solvent was contacted twice with a double volume of simulant (either ANL or ORNL simulant). Successive extraction, scrub and strip steps were carried out by rotating the solutions end-over-end at $50-60 \mathrm{rpm}$ (Glass-Col ${ }^{\oplus}$ laboratory rotator) in Teflon $(8)$ FEP 
tubes for half an hour at $25 \pm 0.2{ }^{\circ} \mathrm{C}$ and centrifuging (Sanyo MSE Mistral 2000R) for 3 minutes at $4000 \mathrm{rpm}$ at $25^{\circ} \mathrm{C}$.

\subsubsection{Electrospray Analysis}

ES-MS was performed on a PE SCIEX API 165 single quadrupole mass spectrometer (Concord, Ontario, Canada) outfitted with a TurbolonSpray source. A $30-\mathrm{cm}$ long, Teflon ${ }^{\circledR}$ encapsulated fused silica transfer tube $(75 \mu \mathrm{m}$-id. fused silica encapsulated in $1 / 16$ in. o.d. Teflon, CETAC Technologies, Inc.) connected a 3.5-cm-long stainless steel ES emitter (400 $\mu \mathrm{m}$ o.d., $100-\mu \mathrm{m}$-i.d.) to the stainless steel $254 \mu \mathrm{m}$-i.d. bore-through bulkhead grounding port built into the source. The emitter held at ca. $4.5 \mathrm{kV}$ was placed $1.5-2.5 \mathrm{~cm}$ from the curtain gas plate aperture and angled to spray across the aperture. Nitrogen was used for sample nebulization. No "turbo gas" was used in these experiments. Sample was introduced to the instrument using a syringe pump to deliver solution loaded into $1.0 \mathrm{~mL}$ plastic syringes (Becton Dickinson Co., Franklin Labs, NJ) at a flow rate of $5.0 \mu \mathrm{L} / \mathrm{min}$. Resulting spectra were the sum of five individual scans from $\mathrm{m} / \mathrm{z} 30-1000$ using a $0.1 \mathrm{~m} / \mathrm{z}$ step size and a $5.0 \mathrm{~ms}$ dwell time. All the electrospray rinses and clean up were done with a mixture of dichloromethane (EM, HPLC grade) and acetonitrile (anhydrous, EM) 50\% - 50\% in volume. Ten-fold dilutions of all the samples were also made with this mixture.

\subsection{RESULTS AND DISCUSSION}

\subsubsection{Overview of the Solvent at Different Stages}

The ES-MS spectra reflected the general expectations regarding major species present in the solvent during the extraction-scrub-strip sequence and pointed at the likely anionic impurity. A blank was first run in order to determine the different peaks introduced by the acetonitriledichloromethane mixture. The spectrum of the pristine solvent in cation mode is shown in Figure 3.1. Overall signal intensity was weak, but it is interesting to note that the most intense peak results from the potassium-BoBCalixC 6 complex, the potassium likely being introduced

during the synthesis of the calixarene. The cation-mode spectrum of the solvent after ten 


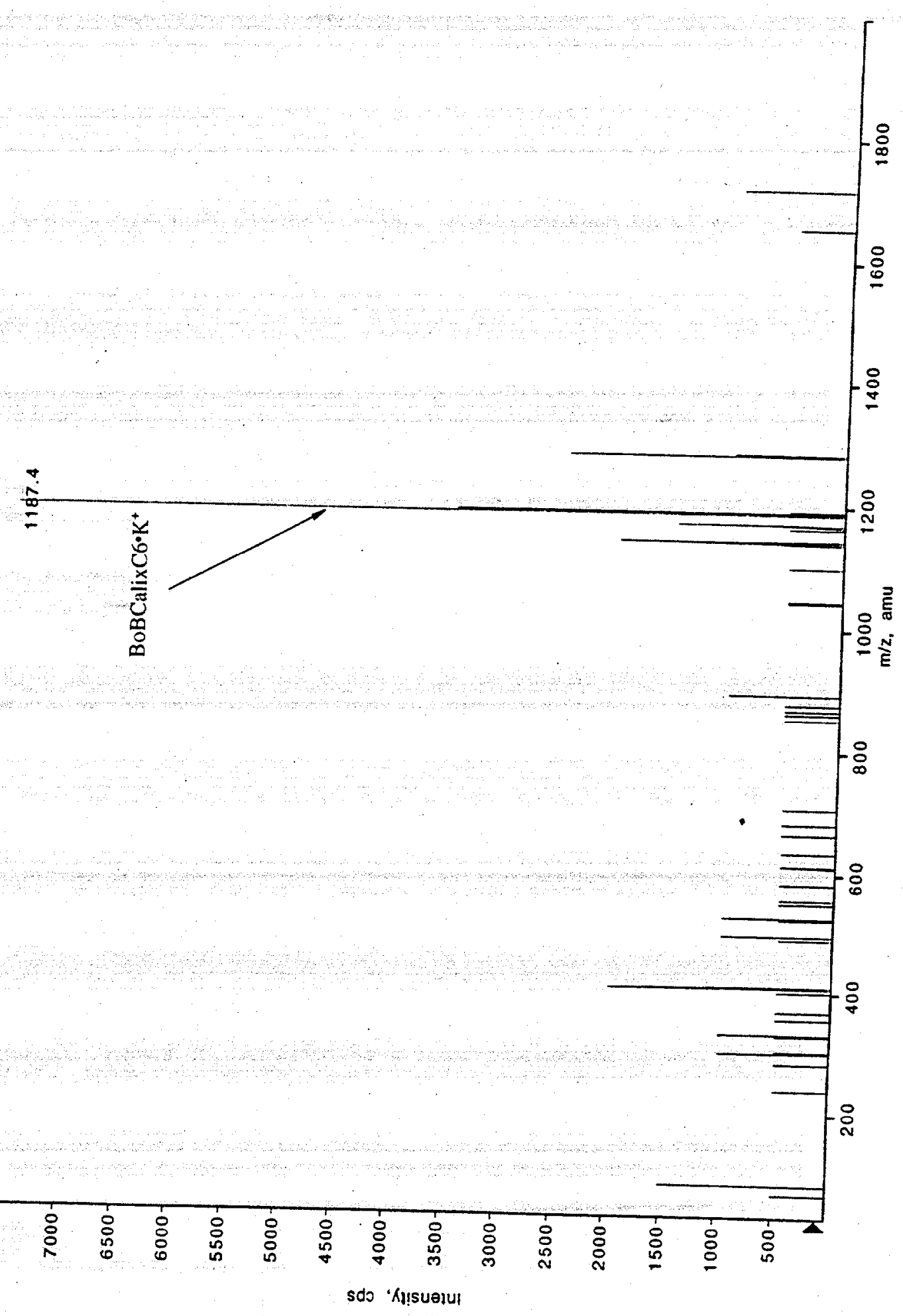

Figure 3.1. Cation-Mode Electrospray Spectrum of the Pristine Solvent. Solvent: BoBCalix $60.01 \mathrm{M}$ and modifier Cs-3 $0.2 \mathrm{M}$ in Isopar ${ }^{\circledR} \mathrm{L}$. 


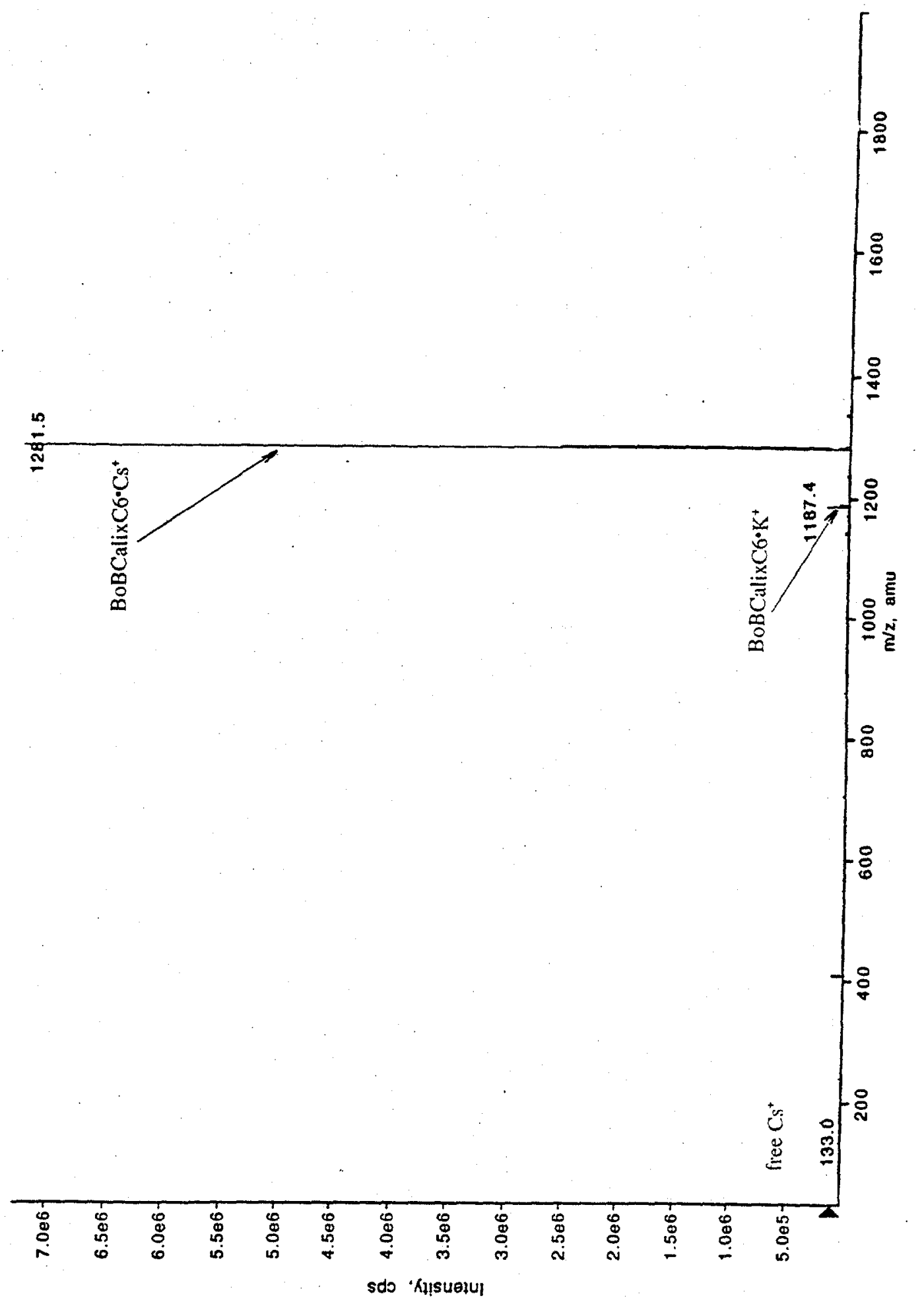

Figure 3.2. Cation-Mode Electrospray Spectrum of the Solvent Contacted 10 times with the ANL Simulant. Solvent: BoBCalixC6 $0.01 \mathrm{M}$ and modifier Cs-3 $0.2 \mathrm{M}$ in Isopar ${ }^{\circledR} \mathrm{L}$ contacted 10 times with $\mathrm{ANL}$ simulant at $\mathrm{O} / \mathrm{A}=0.2$ and $\mathrm{T}=25^{\circ} \mathrm{C}$. 
contacts with ANL simulant shows that cesium is the major cation extracted after contact with the simulant (Figure 3.2). From previous extraction results, it is known that sodium and potassium are weakly extracted, and in spite of the large excess of these two cations in the simulant, the peaks corresponding to their complexes with the calixarene are barely detectable.

In view of the complexity of the simulant, a variety of different anions may be expected to be present in the organic phase. The most complicated spectrum in the anion mode is the one of the solvent after extraction (Figure 3.3). Indeed, a variety of anions together with their adducts with the Cs-3 alcohol modifier could be assigned to peaks. The presence of anionmodifier adducts is consistent with the modifier acting as an anion-solvating agent. Because of the high efficiency of the scrubbing and stripping stages, the corresponding spectra (Figures 3.4 and 3.5) show a disappearance of many peaks, such as those associated with $\mathrm{Al}(\mathrm{OH})_{4}^{-}$, that were intense in the extraction spectrum in the anion mode. It is of interest to observe that, as expected, nitrate is the predominant anion remaining after one scrub and one strip. It was already hypothesized that the impurity would remain in the solvent after the stripping stages and would tend to build-up. That indeed seems to be the case for the doublet of peaks present at molecular weights of 235 and 249. The spectrum of the scrubbed solvent (Figure 3.4) shows a large increase of the relative ratios of these peaks to those corresponding to other anions (the complete identification will be explained below). The same phenomenon is observed with the spectrum of the stripped solvent (Figure 3.5).

\subsubsection{Peak Identifications}

The assignment of the ES-MS peaks is presented by reference to Figure 3.3 (extraction stage), since this spectrum is the most complex. All the peaks found in the other spectra can be interpreted by comparison with it. The peaks originating from the blank solution (acetonitriledichloromethane) are clearly marked on the spectrum.

The spectrum in Figure 3.3 can be divided into three groups. The first group can be found at molecular weights below $300 \mathrm{amu}$, containing all the non-complexed anions. It is uncertain whether they actually exist in the organic phase as discrete anions or as complexes that were 

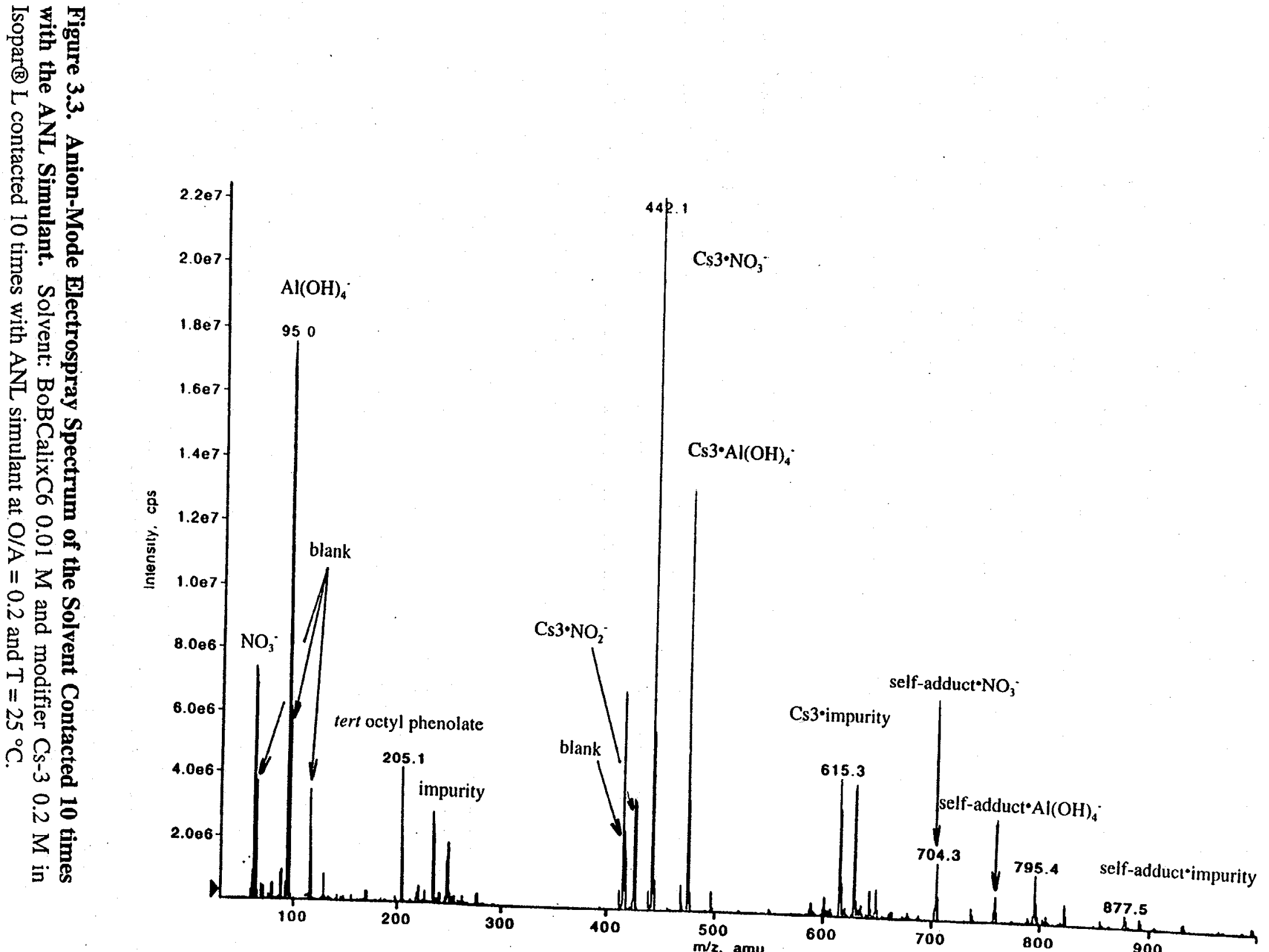


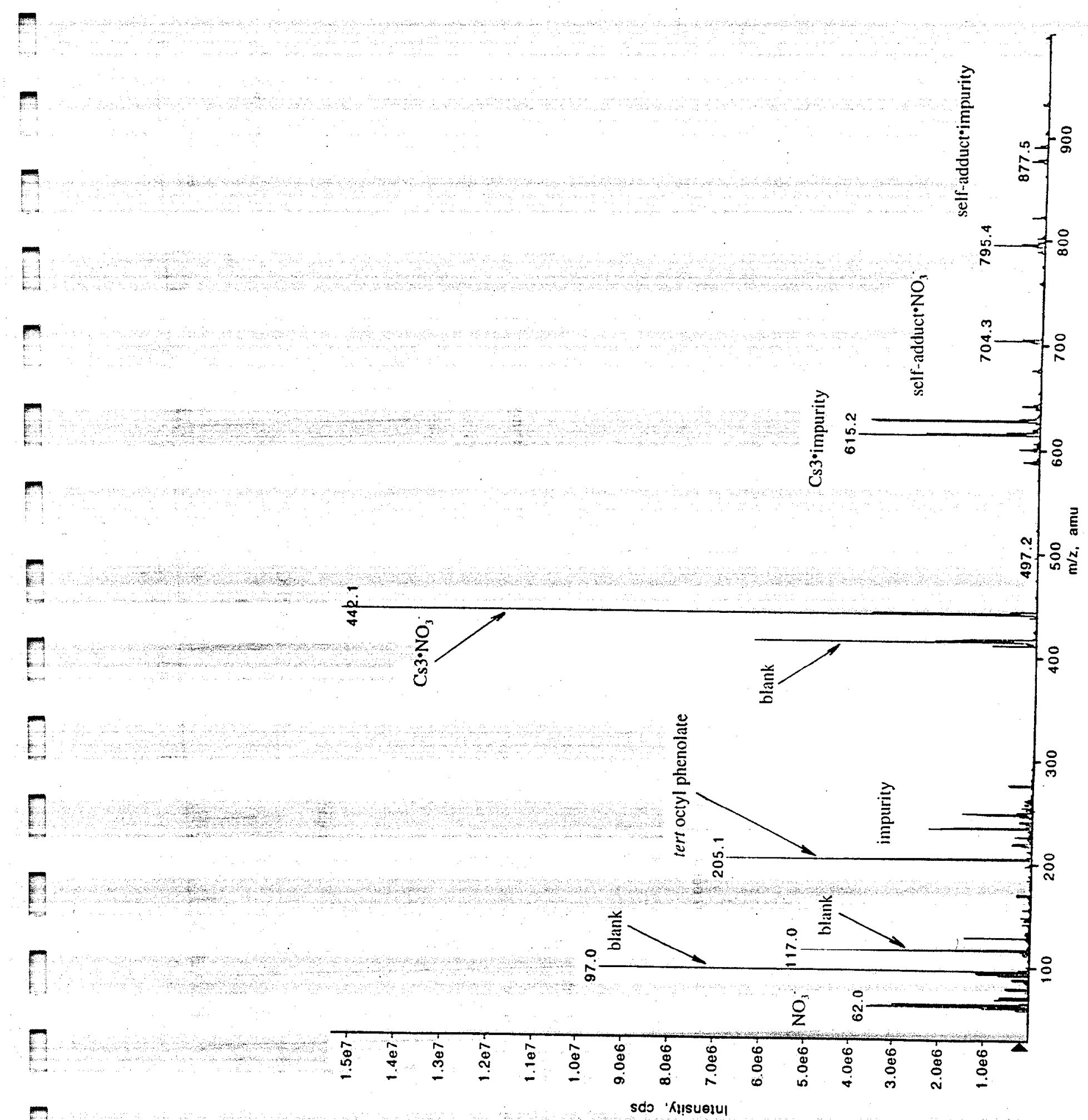

Figure 3.4. Anion-Mode Electrospray Spectrum of the Scrubbed Solvent. Solvent: BoBCalixC6 $0.01 \mathrm{M}$ and modifier Cs-3 $0.2 \mathrm{M}$ in Isopar ${ }^{\circledR} \mathrm{L}$ contacted with ANL simulant then scrubbed with $50 \mathrm{mM}$ nitric acid at $\mathrm{O} / \mathrm{A}=1$ and $\mathrm{T}=25^{\circ} \mathrm{C}$. 


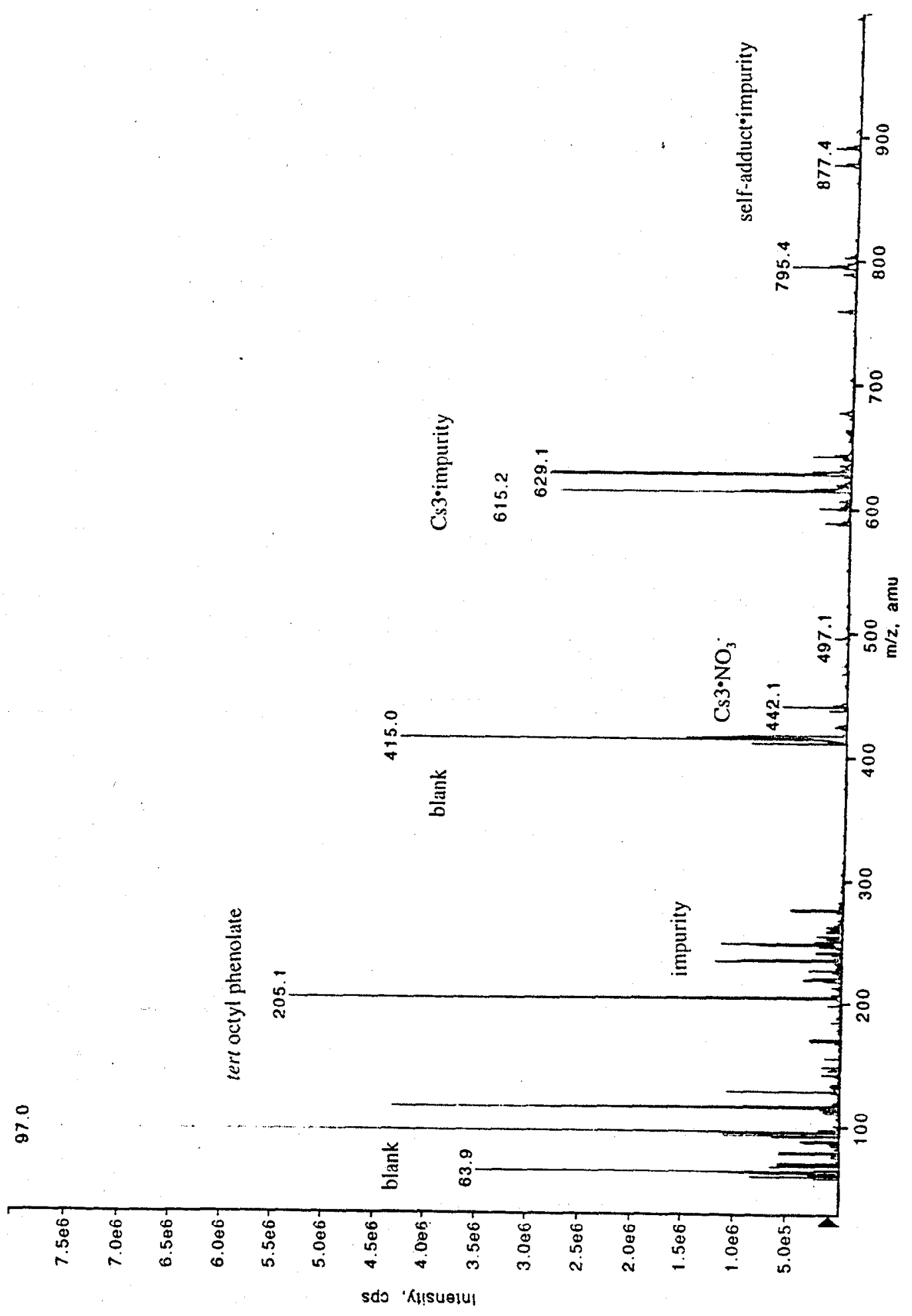

Figure 3.5. Anion-Mode Electrospray Spectrum of the Stripped Solvent. Solvent: BoBCalixC6 $0.01 \mathrm{M}$ and modifier Cs-3 $0.2 \mathrm{M}$ in Isopar ${ }^{\circledR}$ L contacted with ANL simulant, then scrubbed once with $50 \mathrm{mM}$ nitric acid, and then stripped once with 0.5 $\mathrm{mM}$ nitric acid $/ 0.1 \mathrm{mM}$ cesium nitrate at $\mathrm{O} / \mathrm{A}=1$ and $\mathrm{T}=25^{\circ} \mathrm{C}$. 
dissociated by the electrospray technique. Peaks present in the part of the spectrum below 300 amu are assigned to $\mathrm{NO}_{3}^{-}(62 \mathrm{amu}), \mathrm{Al}(\mathrm{OH})_{4}^{-}(95 \mathrm{amu})$, and para-tert-octyl phenolate (205 amu). Nitrite $\left(\mathrm{NO}_{2}{ }^{2}\right)$ is not detected most likely because of its low molecular weight (46 amu). Its complex with the Cs-3 modifier, on the contrary, appears where expected at $426 \mathrm{amu}$ (see below).

The second group of peaks is merely a translation of the first group by $380 \mathrm{amu}$, which corresponds to the molecular weight of the modifier Cs-3. This observation suggests that the anions are solvated in the organic phase by the modifier. Such solvation explains in part the ability of the modifier to enhance the extraction of cesium by the calixarene.

The third group of peaks, possessing relatively weak intensity, again appears as a translation of the first group, this time by $642 \mathrm{amu}$. This molecular weight corresponds to a selfaddition (binary condensation) product obtained upon repeated and prolonged contact of the Cs-3 modifier with the alkaline simulant [15] (Figure 3.6). Most of the anions present in their noncomplexed form are found in the two other solvated groups. Therefore, the assignments of the peaks in the first group, together with the described two translations provide for the assignments of most of the peaks in the entire spectrum.

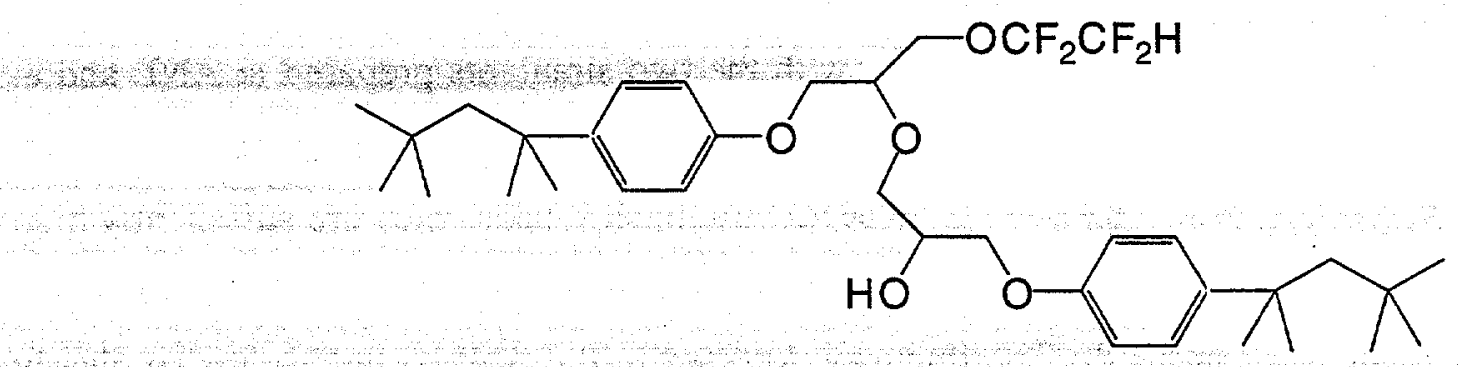

Fígure 3.6. Structure of Cs-3 Condensation Product (Molecular Weight $642 \mathrm{~g} / \mathrm{mol}$ )

The only significant peaks that cannot be readily assigned according to known anionic constituents of the system are those that appear at 235 and 249 amu. Corresponding translation peaks are also found at 615 and 629 amu (adducts with Cs-3 modifier) and at 877 and $891 \mathrm{amu}$ (adducts with the $642 \mathrm{amu}$ Cs-3 condensation product). If the simulant (and as a consequence the solvent) contains some anionic impurities, it follows that their molecular weights are likely 235 and $249 \mathrm{~g} / \mathrm{mol}$. It is interesting to note that as the inorganic anions are washed out of the 
solvent during the scrub (Figure 3.4) and strip (Figure 3.5) contacts, there is a decrease in the population of their adducts with the Cs-3 modifier (442 and 475 amu for the nitrate and tetrahydroxyaluminate adducts, respectively) with a concomitant relative increase in the populations of the Cs-3 adduct with the 235 and 249 amu species at 615 and $629 \mathrm{amu}$. It can be seen that, as the solvent is scrubbed and then stripped, the population of the adducts of the 235 and 249 amu species with both the Cs-3 modifier and the self-adduct increase relative to the peaks corresponding to the free 235 and 249 amu species. This could be because, with the inorganic anions largely washed out of the solvent, the modifier and self-adduct are now more available to form associations with the lipophilic anions comprising the 235 and 249 amu peaks. This observation is also consistent with the result described in Chapter 2 illustrating that washing the simulant with a solution of the Cs-3 modifier in Isopar ${ }^{\circledR} \mathrm{L}$ appears to remove the lipophilic anionic impurity. These results suggest that two anionic impurities (235 and 249 amu) are extracted and cannot be effectively washed from the organic phase by the scrubbing and stripping operations. Their tenacity is promoted by their association with the Cs-3 modifier in the solvent.

\subsubsection{Comparison Between Simulants}

The previous experiment was repeated with the two simulants prepared at ANL and at ORNL, this time involving only two contacts were performed prior to the electrospray analysis. Whereas the intensities of the peaks in these spectra are much weaker, they are sufficiently high to allow comparison to previously discussed spectra. The two spectra (relevant areas) are presented in Figures 3.7 and 3.8. The impurity detected in the ANL simulant is also clearly present in the ORNL simulant, but in quantities approximately 10 times less.

\subsubsection{Identification of the Impurity}

The lipophilic nature of the impurities and the apparent presence of the same anionic impurities in both simulants suggest the possibility of detergent residues. A distinct possibility is that the peaks at 235 and 249 amu correspond to undecyl-and dodecylsulfonate. The 14-amu 


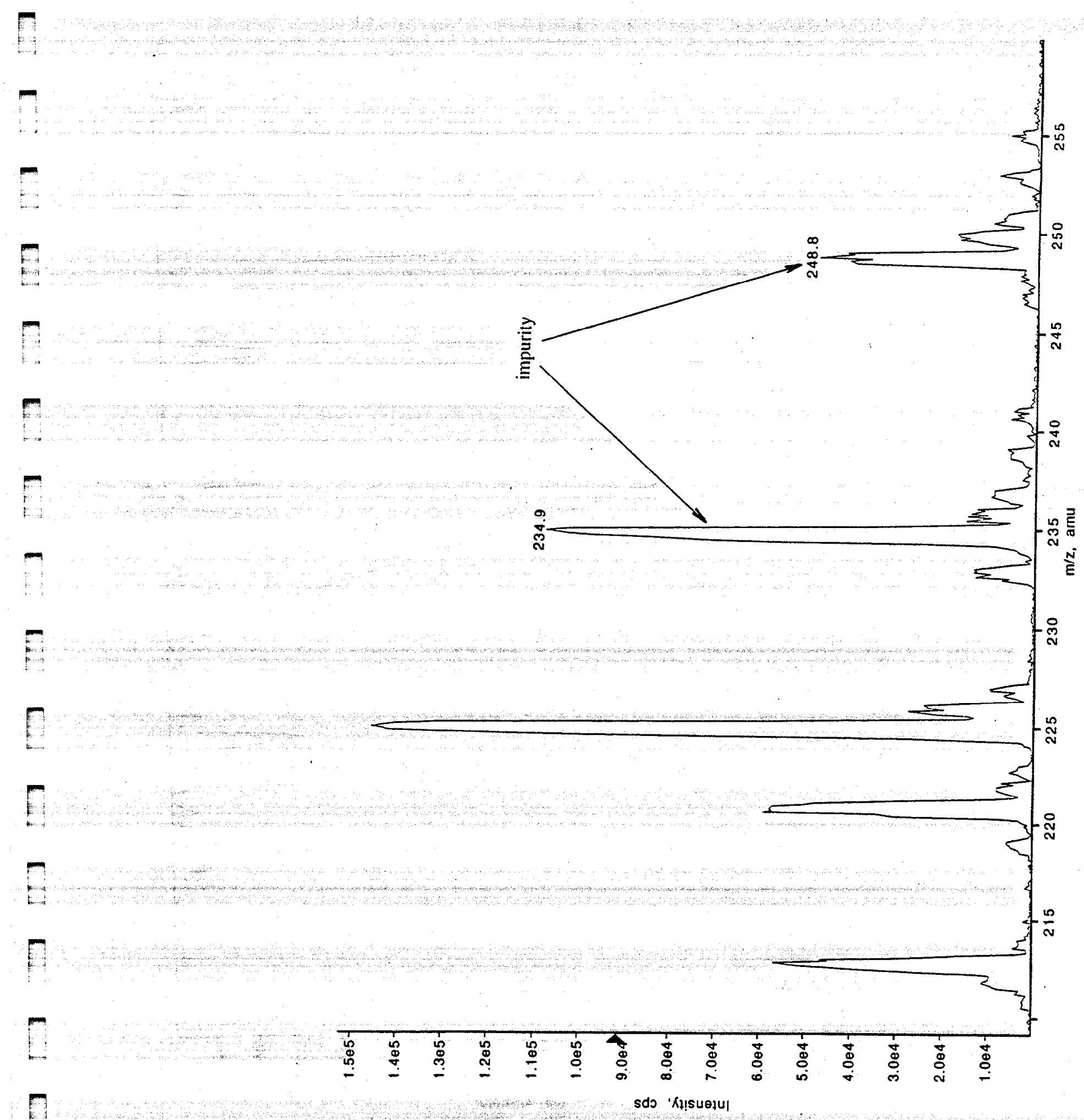

Figure 3.7. Anion-Mode Electrospray Spectrum of the Solvent Contacted Twice with the ANL Simulant. Solvent: BoBCalixC6 $0.01 \mathrm{M}$ and modifier Cs-3 $0.2 \mathrm{M}$ in Isopar $B$ L contacted twice with ANL simulant at $\mathrm{O} / \mathrm{A}=0.2$ and $\mathrm{T}=25^{\circ} \mathrm{C}$. 


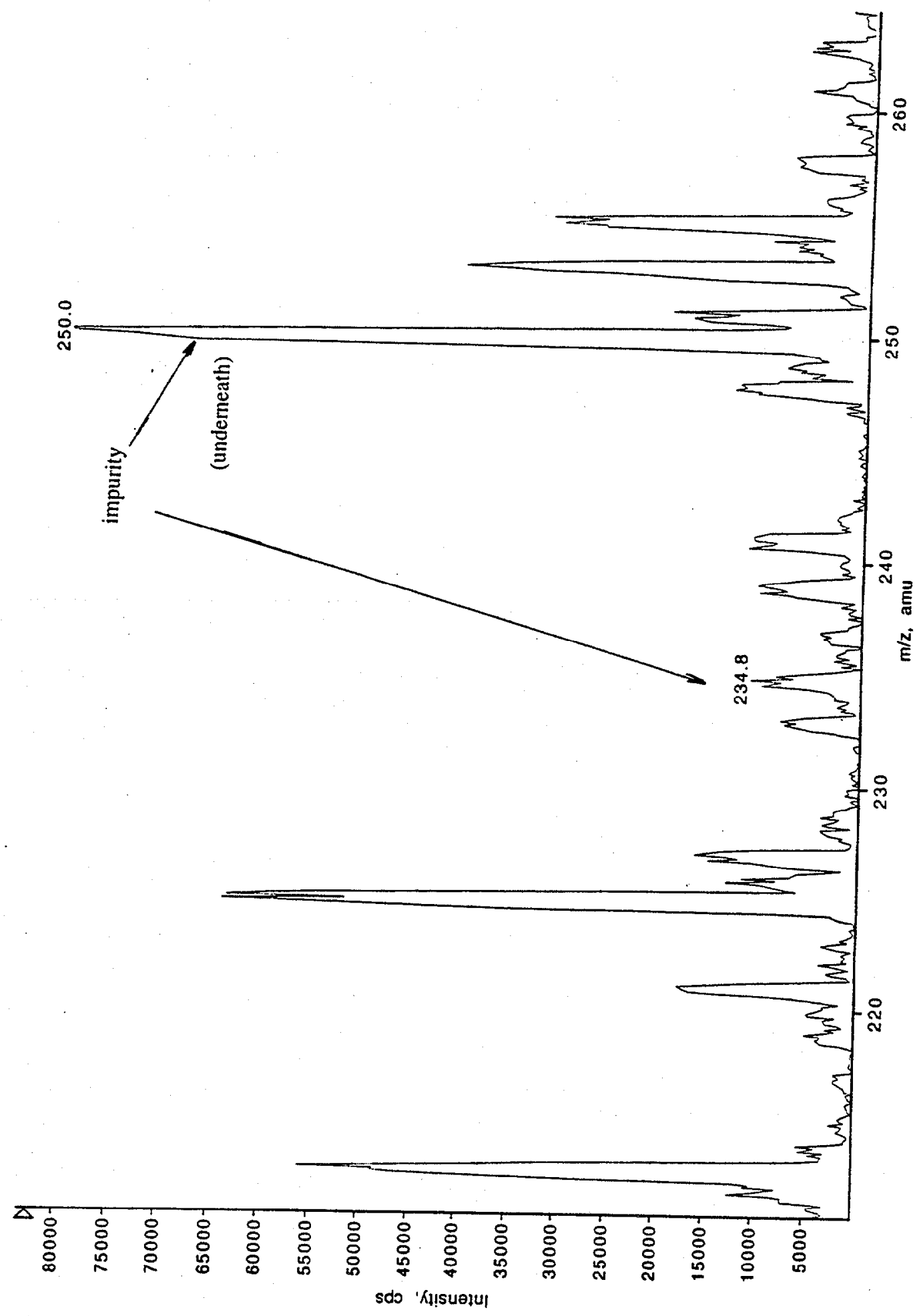

Figure 3.8. Anion-Mode Electrospray Spectrum of the Solvent Contacted Twice with the ORNL Simulant. Solvent: BoBCalixC6 $0.01 \mathrm{M}$ and modifier Cs-3 $0.2 \mathrm{M}$ in Isopar ${ }^{\circledR} \mathrm{L}$ contacted twice with ORNL simulant at $\mathrm{O} / \mathrm{A}=0.2$ and $\mathrm{T}=25^{\circ} \mathrm{C}$. 


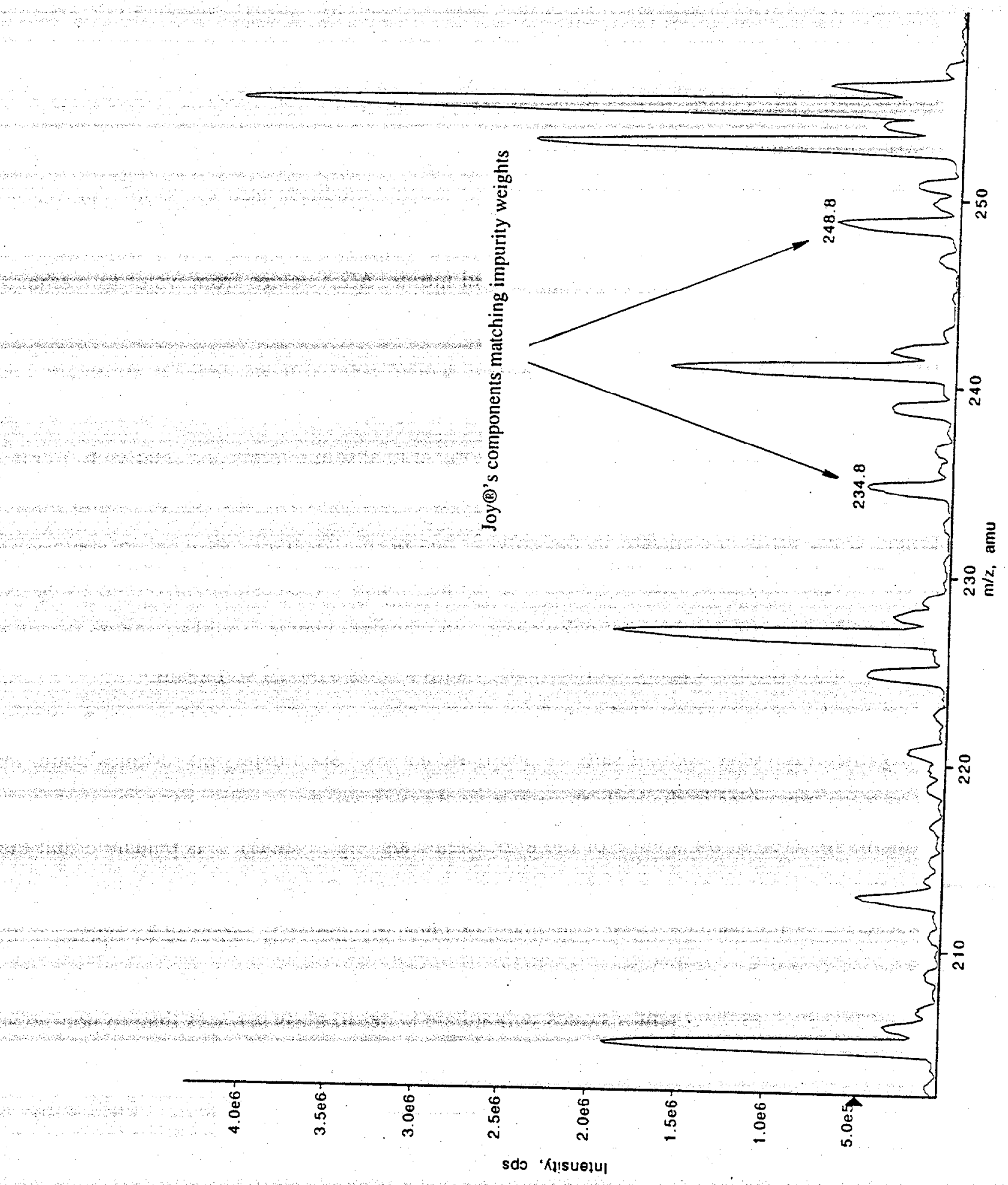

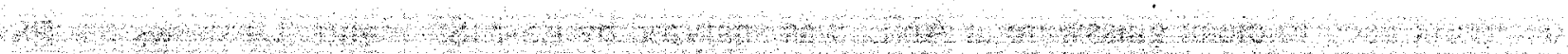

Figure 3.9. Anion-Mode Electrospray Spectrum of a 100,000 dilution of Joy ${ }^{\circledR}$

Liquid Gel. Dilution in deionized water. 
difference seems particularly telling in that it corresponds to a single difference of a methylene unit $-\mathrm{CH}_{2}$ - that would be typical in commercial detergents. The two sulfonate anions would be expected to be lipophilic and well-solvated by the alcohol modifier used in the solvent. Gibbs energies of transfer $\Delta G_{\mathrm{rr}}{ }^{\circ}$ of simple ions may provide a crude estimate of the magnitude of the lipophilicity of dodecylsulfonate. For acetate and nitrate, $\Delta G_{\mathrm{r}}{ }^{\circ}$ values from water to methanol are given as 13 and $16 \mathrm{~kJ} / \mathrm{mol}$, respectively [16]. If we make the assumptions that the methanol approximates the solvation of Cs-3 modifier, that acetate approximates methane sulfonate, and that each aliphatic carbon adds $-2.8 \mathrm{~kJ} / \mathrm{mol}$ to $\Delta G_{\text {tr }}{ }^{\circ}$ [17], one may see that transfer of the dodecylsulfonate to the solvent is likely very favorable in absolute terms and relative to nitrate. Thus, it is understandable how these surfactant anions introduced to the solvent could hinder stripping. Once all of the nitrate in the solvent has been effectively stripped in stage-wise operation, leaving only the surfactant anions as counter ions for the cesium-calixarene complex, stripping would be expected to practically cease. In the next chapter, it will be shown that this expectation can be validated using sodium dodecylsulfonate as a model surfactant.

As for the initial source of the surfactant impurities, no definitive answer exists. Soaps and detergents commonly contain salts of lipophilic anions. Such detergent residues could be present as trace impurities in the bulk chemicals used to prepare the various simulants, and since the simulants differed in the source of the bulk chemicals (e.g., $\mathrm{NaOH}$ ), it is plausible that the detergent residue level in the simulants would differ as well. Since detergents are also used to clean glassware and other laboratory containers, residues incompletely removed by rinsing with distilled water are likely sources of contamination of laboratory solutions. It is also possible that charged species such as detergent residues will adhere better to glass surfaces than to non-polar surfaces such as Teflon $^{\circledR} \mathrm{FEP}$, and thus the type of lab-ware used to prepare the simulants may contribute to variations in the amount of detergent residues present. Following a recommendation from our collaborators at ANL, a sample of Joy ${ }^{\circledast}$ detergent, the brand of detergent used to clean glassware at ANL, was analyzed by ES-MS. Figure 3.9 shows the ESMS spectrum of a $10^{5}$ dilution in water of a sample of this particular brand of detergent that was available at ORNL. The detergent was analyzed to determine whether the peaks at 235 and 249 amu (assigned to undecyl- and dodecylsulfonate) found in the simulant and solvent, or perhaps variants (e.g., chain-length homologs), would be present in a common detergent. As can be seen in Figure 3.9, peaks at 235 and 249 amu (as well as many other peaks) are present in the 
spectrum, indicating a possibility that a detergent, possibly Joy ${ }^{\circledR}$, might be the source of these sulfonate anions.

\subsection{CONCLUSIONS}

The conclusions that may be made from the ES-MS experiments are as follows:

- The lipophilic impurity in the simulants is likely a mixture of undecyl- and dodecylsulfonate.

- The cesium complex in the solvent is a simple 1:1 cesium-calixarene complex mono-cation.

- The anions are present in three forms: free, complexed with one molecule of Cs-3 alcohol, and complexed with a self-adduct of Cs-3 (a degradation product).

- Although various anions are extracted, scrubbing removes all but nitrate and the lipophilic impurity anions.

- On stripping, the lipophilic impurity anions predominate.

In the next chapter, the results of solvent-extraction experiments used to test the effect of dodecylsulfonate as a model impurity anion are discussed. 


\section{QUANTIFICATION AND REMEDIATION}

\subsection{INTRODUCTION}

As shown above, alkyl sulfonates, lipophilic anions omnipresent in detergents, were determined by electrospray mass spectrometry to be present in solvents that displayed relatively poor behavior on stripping. To confirm that the presence of alkyl sulfonates in the solvent does in fact negatively impact stripping performance, pristine solvent was contacted with simulant or stripping solution containing authentic sodium dodecylsulfonate at various concentrations. The cesium distribution coefficients obtained using simulants spiked with sodium dodecylsulfonate were also compared to those obtained with the simulants believed to contain alkyl sulfonate impurities. Another point of interest is to approximate the quantity of sulfonate impurity present in the affected simulants. Finally, the analysis of the problem will allow a possible remediation through the incorporation of trioctylamine in the solvent. As was previously discussed, the effects produced by the impurity had been shown to be suppressed by the use of a trialkylamine [1].

\subsection{EXPERIMENTAL}

\subsubsection{Materials and Preparation of Solutions}

Three types of experiments were performed, requiring three different solutions. A stock solution of sodium dodecylsulfonate (Aldrich, $99+\%$ ) at $10^{-2} \mathrm{M}$ in $0.5 \mathrm{mM}$ nitric acid containing cesium nitrate at $0.1 \mathrm{mM}$ was prepared and used for subsequent dilutions (with $0.5 \mathrm{mM}$ nitric acid/0.1 mM cesium nitrate). These solutions were used to check the effects of the presence of the sulfonate anion in the strip solution on the cesium distribution ratios and to establish the possibility of remediation by the trioctylamine (TOA). The corresponding organic phases containing $10^{-4} \mathrm{M}$ and $10^{-3} \mathrm{M}$ TOA were prepared as new small batches of solvent. The experiment designed to generate a standard curve to be used to quantify the level of impurity present in the ANL simulant was performed with three solutions of ORNL simulant spiked with known volumes of sodium dodecylsulfonate (from a stock solution of sulfonate $10^{-2} \mathrm{M}$ in water). 
The volume added was small enough not to have an influence on other component concentrations.

\subsubsection{Contacting Procedures}

The experiments showing the influence of the sulfonate presence on cesium distribution ratios and the remediation with TOA were performed as " $D_{\mathrm{Cs}}$ forward" experiments. The procedure was described in Section 2.2.2. The approximation of the impurity concentration was achieved through a batch experiment (see 2.1.2)

\subsection{RESULTS AND DISCUSSION}

\subsubsection{Effect of Dodecylsulfonate Anion on Cesium Extraction}

The experiments investigating the effects of the presence of dodecylsulfonate ion involved obtaining cesium distribution ratios under stripping conditions ("forward" $D_{\mathrm{Cs}}$ experiments). Controlled amounts of sulfonate in the sodium salt form were added to the aqueous phase containing nitric acid $0.5 \mathrm{mM}$ and cesium nitrate $0.1 \mathrm{mM}$ (stripping solution). Cesium distribution ratios obtained under these conditions are presented in Figure 4.1. The effects of extremely low amounts of sulfonate (under $10^{-5} \mathrm{M}$ ) are already detectable. A quantity of sulfonate greater than $10^{-4} \mathrm{M}$ results in a quantitative extraction of cesium by the calixarene. Any sulfonate concentration greater than $10^{-5} \mathrm{M}$ in a system would thus prohibit efficient stripping. This result confirms that traces of impurities were sufficient to produce high stripping values when using the ANL simulant. In addition, the cesium distribution ratio of 0.04 usually obtained for the second strip in the extraction-scrub-strip sequence using ORNL simulant corresponds to the $D_{\mathrm{Cs}}$ value obtained for a concentration of dodecylsulfonate 10 times lower than the one required for a distribution ratio of 0.2 . This is consistent with the observations by ES-MS. 


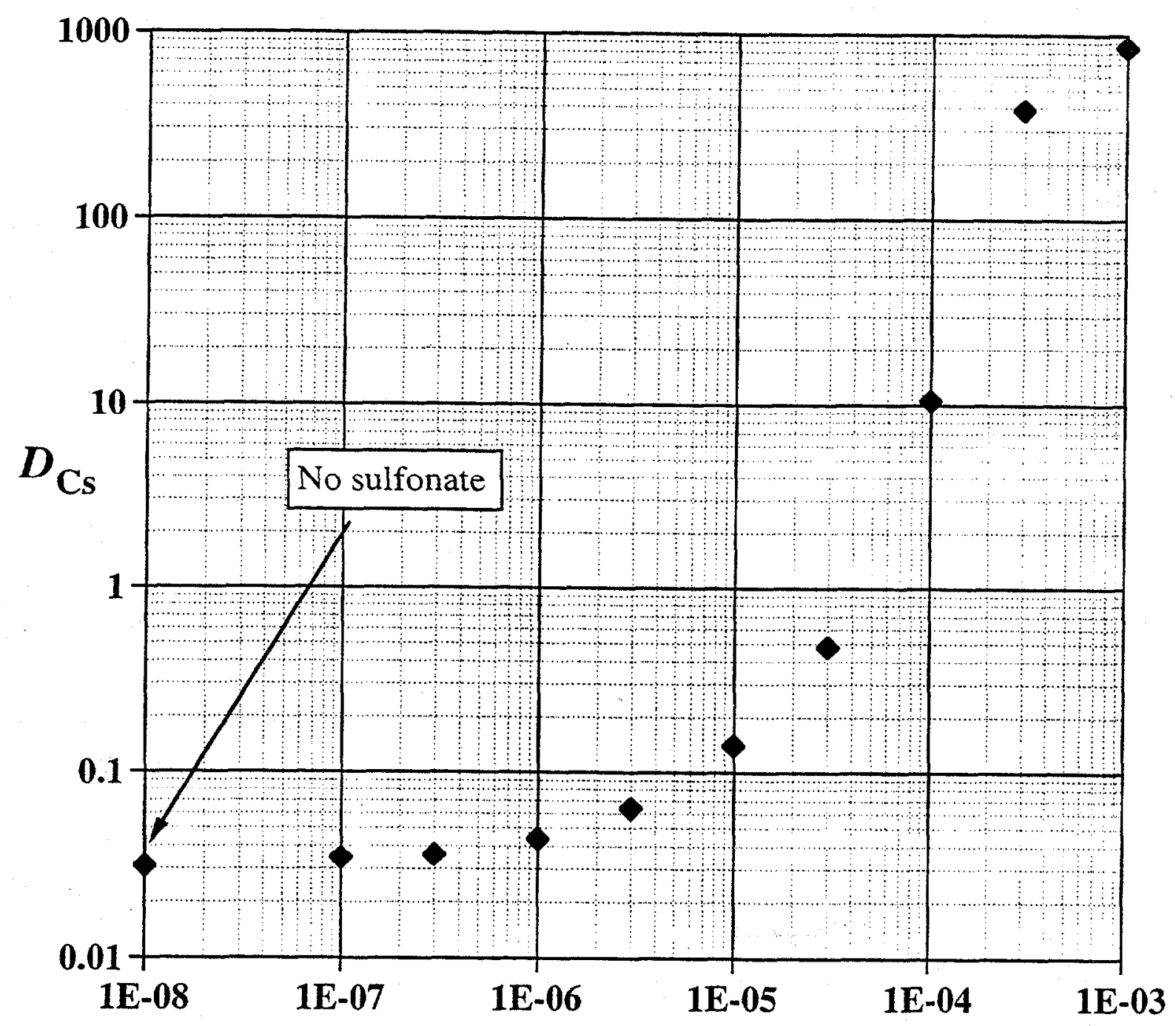

\section{Initial concentration of dodecylsulfonate in the aqueous phase $(\mathrm{mol} / \mathrm{L})$}

Figure 4.1. Effect of Dodecylsulfonate Anion on Cesium Distribution Ratios Under Stripping Conditions. Organic phase: $[\mathrm{BoBCalix} 66]=$ $0.01 \mathrm{M}$ and $[\mathrm{Cs}-3]=0.2 \mathrm{M}$ in Isopar®L. Aqueous phase: $\left[\mathrm{CsNO}_{3}\right]=0.1$ $\mathrm{mM}$ and $\left[\mathrm{HNO}_{3}\right]=0.5 \mathrm{mM}$. Contacts were made at $\mathrm{O} / \mathrm{A}$ ratio $=1(0.75$ $\mathrm{mL}$ of each phase) and $\mathrm{T}=25^{\circ} \mathrm{C}$ with varying concentations of dodecylsulfonate added to the aqueous phase. 


\subsubsection{Approximation of the Quantity of Sulfonate Present in ANL Simulant}

The previous experiment showed that the effects of minute amounts of sulfonate present in the system are dramatic. A concentration of dodecylsulfonate equal to $1.3 \times 10^{-5} \mathrm{M}$ is sufficient to obtain $D_{\mathrm{Cs}}$ values in a "forward" experiment comparable to the ones obtained on stripping with ANL simulant (Table 2.6). When progressing through the procedure in Table 4.1, the solvent is contacted twice with the simulant. If it is assumed that the sulfonate is entirely extracted by the solvent during the extraction stages and does not partition during the scrubbing steps, one can estimate that the quantity of impurity present initially in the simulant is approximately $6.5 \times 10^{-6} \mathrm{M}$. To examine the effect of dodecyl sulfonate on $D_{\mathrm{Cs}}$ values in sequential contacting, three solutions of ORNL simulant spiked with different concentrations of sodium dodecylsulfonate $\left(10^{-6} \mathrm{M}, 6.5 \times 10^{-6} \mathrm{M}\right.$, and $\left.10^{-5} \mathrm{M}\right)$ were prepared. Two extraction steps for each simulant solution were followed by two scrubs and three strips. The results are reported in Table 4.1 .

\section{Table 4.1. Cesium Distribution Ratios in Batch Tests Involving ORNL Simulant Containing Controlled Amounts of Sulfonate ${ }^{a}$}

\begin{tabular}{|c|c|c|c|c|}
\hline \multirow[t]{2}{*}{ Operation } & \multicolumn{4}{|c|}{$D_{\mathrm{Cs}}$} \\
\hline & ORNL simulant & $\begin{array}{l}\text { ORNL simulant + } \\
10^{-6} \mathrm{M} \text { sulfonate }\end{array}$ & $\begin{array}{l}\text { ORNL simulant }+ \\
6.5 \times 10^{-6} \mathrm{M} \text { sulfonate }\end{array}$ & $\begin{array}{l}\text { ORNL simulant + } \\
10^{-5} \mathrm{M} \text { sulfonate }\end{array}$ \\
\hline $1^{\text {st }}$ Extraction & 11.78 & 11.66 & 11.94 & 11.78 \\
\hline $2^{\text {nd }}$ Extraction & 10.97 & 10.88 & 11.01 & 10.92 \\
\hline Scrub & 0.705 & 0.701 & 0.711 & 0.730 \\
\hline $1^{\text {st }}$ Strip & 0.035 & 0.036 & 0.050 & 0.060 \\
\hline $2^{\text {nd }}$ Strip & 0.061 & 0.065 & 0.102 & 0.129 \\
\hline $3^{\text {rd }}$ Strip & 0.066 & 0.069 & 0.104 & 0.135 \\
\hline
\end{tabular}

\footnotetext{
a Organic phase: BoBCalixC6 0.01 M + modifier Cs-3 $0.2 \mathrm{M}$ in Isopar $(\mathrm{L}$. Aqueous phases: ORNL simulant (with different concentration of sulfonate) for the extractions, $50 \mathrm{mM}$ nitric acid for the scrub, $0.5 \mathrm{mM}$ nitric acid +0.1 $\mathrm{mM}$ cesium nitrate for the strips. Contacts were run at $25^{\circ} \mathrm{C}$ and $\mathrm{O} / \mathrm{A}=1$.
} 
It may be readily seen that trace concentrations of dodecyl sulfonate in the simulant indeed have a marked effect on stripping performance. However, the concentrations of dodecyl sulfonate in the simulant necessary to raise $D_{\mathrm{Cs}}$ on stripping to the level of the ANL simulant (Table 2.6) would be significantly larger than the $6.5 \times 10^{-6} \mathrm{M}$ estimated from "forward" stripping (Fig. 4.1). This may indicate that the sulfonate may not be entirely extracted from the simulant and may also partition somewhat during the scrubbing and stripping stages. Therefore, the remaining quantity of lipophilic anion in the stripping stages would be less than anticipated. Overall, the experiment confirms that only minute amounts of soap residues would need to be present in the ANL simulant to render stripping less effective. The effect of dodecyl sulfonate is regarded to be of the correct magnitude to account for the difficulty with stripping with the ANL simulant.

\subsubsection{Remediation with Trioctylamine}

In view of the probable identity of the anionic impurities that hinder stripping, one can understand the action of trioctylamine in blocking that effect (see Section 2.3.5). As before, cesium distribution ratios were measured under stripping conditions (forward $D_{\mathrm{Cs}}$ experiments) using a spike of sodium dodecylsulfonate in various concentrations in the aqueous phase. The solvent contained either no TOA or TOA at $10^{-4}$ or $10^{-3} \mathrm{M}$. The dramatic blocking effect is shown in Figure 4.2. It may be seen that a TOA concentration at ten times the aqueous sulfonate concentration suffices to suppress the impurity effect nearly completely. The fact that the TOA does not appear to be acting stoichiometrically may simply reflect the incomplete conversion of the amine to the ammonium form, which would likely require higher acidities.

\subsection{CONCLUSIONS AND FURTHER DEVELOPMENTS}

Solvent-extraction experiments showed that dodecylsulfonate could approximately account for the impurity effect observed using simulants. Minute amounts of this impurity can cause a significant decrease in cesium stripping performance, as proven by the controlled addition of sulfonate in the simulant. The effect of an impurity in the system can be blocked by 


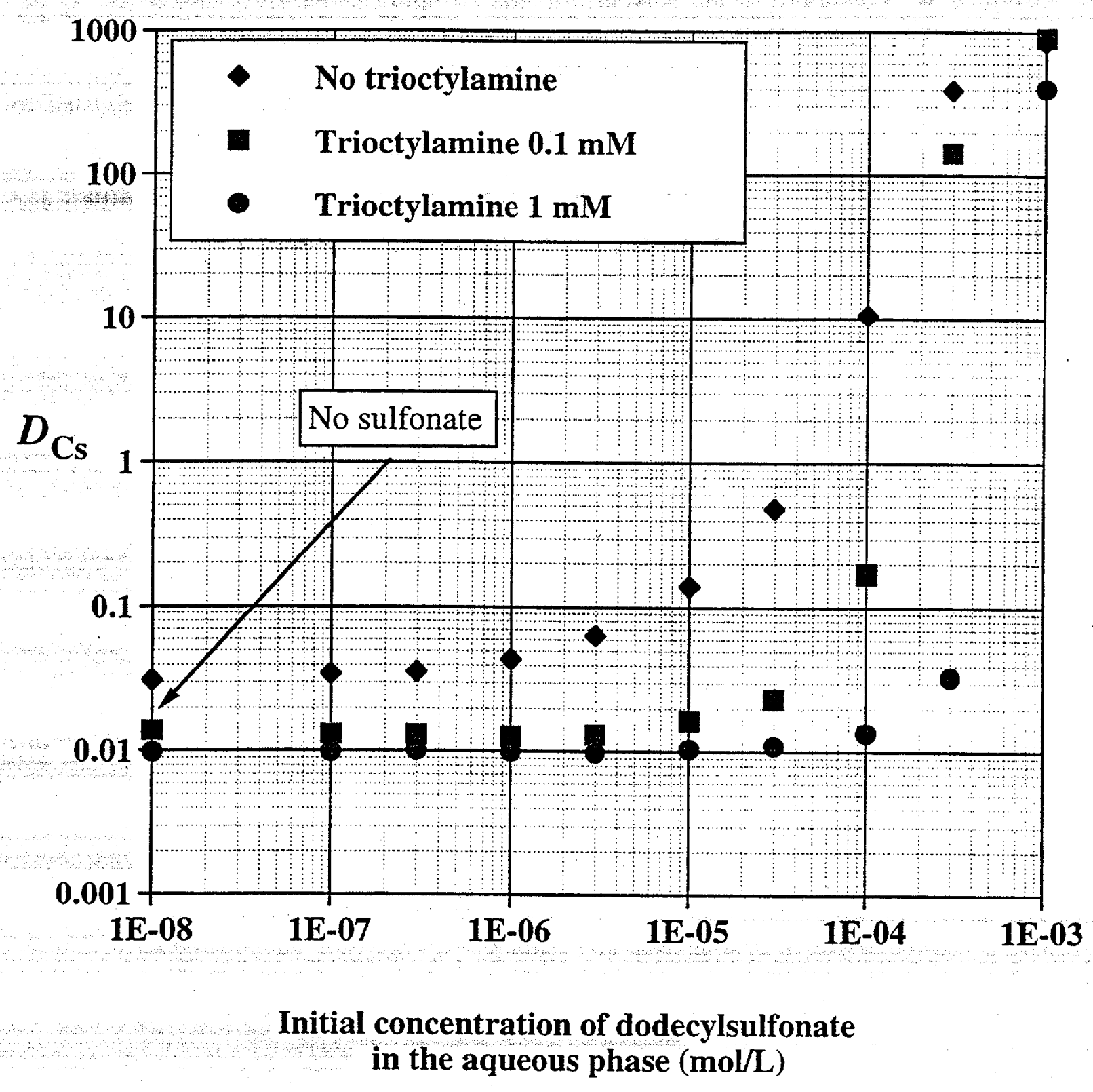

Figure 4.2. Effect of TOA on Cesium Extraction in the Presence of Dodecylsulfonate Anion. Organic phase: $[\mathrm{BoBCalixC} 6]=0.01 \mathrm{M}$, [Cs-3] $=0.2 \mathrm{M}$, and trioctylamine in Isopar ${ }^{\circledR L}$. Aqueous phase: $\left[\mathrm{CsNO}_{3}\right]=0.1$ $\mathrm{mM}$ and $\left[\mathrm{HNO}_{3}\right]=0.5 \mathrm{mM}$. Contacts were made at $\mathrm{O} / \mathrm{A}$ ratio $=1(0.75 \mathrm{~mL}$ of each phase) and $\mathrm{T}=25{ }^{\circ} \mathrm{C}$ with varying concentations of dodecylsulfonate added to the aqueous phase. 
the addition of trioctylamine to the solvent. In the stripping steps occurring under acidic conditions, the amine is partly protonated and replaces cesium as the impurity counter-ion, allowing cesium stripping efficiency to remain excellent. These studies have thereby led to improvements in the solvent composition, resulting in a more robust solvent able to achieve performance meeting SRS requirements. A preliminary report has been submitted for publication [2]. Complete details about these and other improvements will be given in future publications. 


\section{REFERENCES}

[1] Bonnesen, P.V.; Delmau, L.H.; Haverlock, T.J.; and Moyer, B.A. Alkaline-Side Extraction of Cesium from Savannah River Tank Waste Using a Calixarene-Crown Ether Extractant; Report ORNL/TM-13704, Oak Ridge National Laboratory: Oak Ridge, TN, December, 1998

[2] Moyer, B.A.; Bonnesen, P.V.; Delmau, L.H.; Haverlock, T.J.; Sachleben, R.A.; Leonard, R.A.; Conner, C.; Lumetta, G.J. "Solvent Extraction of Tc and Cs from Alkaline Nitrate Wastes," Proc. Internat. Solvent Extraction Conference (ISEC '99), Barcelona, Spain, July 11-16, 1999 (In Press).

[3] Application to U.S. Patent Office: Moyer, B.A.; Bonnesen, P.V.; Sachleben, R.A.;

Presley, D.J. "Solvent and Process for Extracting Cesium from Alkaline Waste Solutions," Ser. No. 09/146,800, Sept. 3, 1998.

[4] Bonnesen, P.V.; Haverlock, T.J.; Engle, N.L.; Sachleben, R.A.; Moyer B.A. "Development of Process Chemistry for the Removal of Cesium from Acidic Nuclear Waste by Calix [4]arene-Crown-6 Ethers," in Calixarene Molecules for Separations, G. J. Lumetta and R. D. Rogers, Eds., ACS Symposium Series, American Chemical Society, Washington, D. C. (In Press).

[5] Dozol, J.-F.; Böhmer, V.; McKervey, A.; Lopez Calahorra, F.; Reinhoudt, D.; Schwing, M.-J.; Ungaro, R.; Wipff, G. New Macrocyclic Extractants for Radioactive Waste Treatment: Ionizable Crown Ethers and Functionalized Calixarenes, Report EUR-17615, European Community, Luxembourg, 1997

[6] Casnati, A.; Pochini, A.; Ungaro, R.; Ugozzoli, F.; Arnaud, F.; Fanni, S.; Schwing, M.-J.; Egberink, R.J.M.; de Jong, F.; Reinhoudt, D.N. J. Am. Chem. Soc., 1995, 117, 2767 
[7] Hill, C.; Dozol, J.-F.; Lamare, V.; Rouquette, H.; Eymard, S.; Tournois, B.; Vicens, J.; Asfari, Z.; Bressot, C.; Ungaro, R.; Casnati, A. J. Inclusion Phenom. Mol. Recognit. Chem., 1994, 19, 399

[8] Bonnesen, P.V.; Delmau, L.H.; Moyer, B.A; Leonard, R.A. (Manuscript to be submitted to Solvent Extr. Ion Exch.)

[9] Delmau, L.H.; Bonnesen, P.V.; Moyer, B.A. Sep. Sci. Technol., to be submitted

[10] Reference 1, Chapter 7.

[11] Crawford, C.L.; Fondeur, F.F.; Peterson, R.A.; White, T.L. Radiation Stability of Calixarene Based Solvent System; Report WSRC-TR-98-00371; Westinghouse Savannah River Co.: Aiken, SC, October 2, 1998.

[12] Reference 1, Chapter 6.

[13] Leonard, R. A., Conner, C., M. W. Liberatore, Sedlet, J., Aase, S. B., and Vandegrift, G. F. Evaluation of an Alkaline-Side Solvent Extraction Process for Cesium Removal from SRS Tank Waste using Laboratory-Scale Centrifugal Contactors, Report ANL-99/14, Argonne National Laboratory, Argonne, Il, August 1999 (in press).

[14] Reference 1, Chapter 3.

[15] Haverlock, T.J.; Bonnesen, P.V.; Sachleben, R.A.; Moyer, B.A. J. Inclusion Phenom. Mol. Recognit. Chem. (In press).

[16] Marcus, Y. Ion Properties; Marcel Dekker: New York, 1997.

[17] Hansch, C.; Leo, J. Substituent Constants for Correlation Analysis in Chemistry and Biology; Wiley-Interscience: New York, 1979. 


\section{INTERNAL DISTRIBUTION}

1. C.W. Alexander

2-3. P.V. Bonnesen

4. G.M Brown

5. J. C. Bryan

6. C.F. Coleman

7. J.L Collins

8-12. L.H. Delmau

13. C.W. Forsberg

14. R.D. Hunt

15. R.T. Jubin

16. C.M. Kendrick

17. T.M. Kent

18. T.J. Keever

19. D.D. Lee
20. C.P. McGinnis

21-46. B.A. Moyer

47. T.E. Myrick

48. R.A. Sachleben

49. B.B. Spencer

50. G.J. Van Berkel

51. J.S. Watson

52. T.D. Welch

53-54. ORNL Laboratory Records

55. ORNL Laboraory Records, RC

56. ORNL Patent Section

57. Y-12 Technical Library

Document Reference Center

58-59. Central Research Library

\section{EXTERNAL DISTRIBUTION}

60-65. Argonne National Laboratory, 9700 South Cass Ave., Argonne, II 60439-4831.

C. Conner

M.L. Dietz

R.A. Leonard

K.L. Nash

J. Sedlet

G.F. Vandegrift

66-67. BNFL, Inc., 2940 George Washington Way, Richland, WA 99352

M.E. Johnson

S. Tumer

68-69. Department of Energy, Savannah River Site, P.O. Box A, Aiken, SC 29802

J.W. McCullough, Jr

P.C. Suggs

70-72. Idaho National Engineering and Environmental Laboratory, Idaho Falls, ID 83415

D.A. Knecht

B.J. Mincher

T.A. Todd

73-74. Lockheed Martin Hanford Corporation (LMHC), S7-85, P.O. Box 1500, Richland, WA 99352-1505.

J.N. Appel

J.O. Honeyman 
75-78. Numatec Hanford Corp., Richland, WA 99352

R.A. Kirkbride

D.L. Herting (P.O. Box 1300, T6-07)

D.L. Penwell

G.L. Troyer

79. Office of Assistant Manager, Energy Research and Development, DOE-ORO, P.O. Box 2008, Oak Ridge, TN 37831-6269

J.L. Harness

80-81. Office of Scientific and Technical Information, P.O. Box 62, Oak Ridge, TN 37831

82-93. Pacific Northwest National Laboratory, P.O. Box 999, Richland, WA 99352

D.L. Blanchard

K.P. Brooks

T.M. Brouns

R.L. Gilchrist

B.P. Hay

L.K. Holton

W.L. Kuhn

D.E. Kurath

M.E. Lerchen

G.J. Lumetta

R.K. Quinn

B.M. Rapko

94-106. Westinghouse Savannah River Co., Aiken, SC 29802

J.T. Carter

H.H. Elder

S.D. Fink

D.T. Hobbs

M.E. Hodges

L.M. Papouchado

R.A. Peterson

S.F. Piccolo

K.J. Rueter

P.L. Rutland

W.L. Tamosaitis

M.C. Thompson

T.L. White

107. H. Babad, 2540 Cordoba Court, Richland, WA 99352-1609

108. M. Baxter-Parrott, 2101 Constitution Avenue NW, Washington, DC 20418 
109. J. T. Case, U.S. Dept of Energy, Idaho Operations Office, 785 DOE Drive, Idaho Falls, ID 83401

110. R.M. Chamberlin, Los Alamos National Laboratory, CST-11, MS J514 Los Alamos, NM 87545

112. J.-F. Dozol, CEA Cadarache DESD/SEP/LPTE, 13108 St Paul lez Durance Cedex, France

113. J.T. Davis, Department of Chemistry and Biochemistry, University of Maryland at College Park, College Park, MD 20742

114. E.P. Horwitz, Eichrom Industries, 8205 S. Cass Ave., Suite 107, Darien, IL, 60561

115. S.R. Izatt, IBC Advanced Technologies, Inc., P.O. Box 98, 856 East Utah Valley Dr., American Fork, Utah 84003

116. J.L. Kovach, NUCON, 7000 Huntley Rd., Columbus, OH 43229

115. J.D. Lamb, Department of Chemistry, 207 ESC, Brigham Young University, Provo, UT 84602

117. R. Ludwig, FU Berlin, Inst. f. Inorg. and Analyt. Chemistry, Fabeckstr. 34-36, 14195 Berlin, Germany

118. C. Madic, Commissariat a l'Energie Atomique, DCC, CEA-Saclay, 91191 Gif-s-Yvette, France

119. J. McGlynn, SAIC, 555 Quince Orchard Road, Suite 500, Gaithersburg, MD 20878

120. R.L. Miller, Los Alamos National Laboratory, CST-11, MS J514, Los Alamos, NM 87545

121. W. W. Schulz, 5314 Arbustos Ct., Albuquerque, NM 87111

122. J.L. Swanson, 1318 Cottonwood Dr., Richland, WA 99352 
123. I. Tasker, Universe Technologies, 9 East second Street, Frederick, Maryland 21701

124. L.L. Tavlarides, Syracuse University, Dept. of Chemical Engineering, 320 Hinds Hall, Syracuse, NY 13244-1190

125. V. Van Brunt, Dept. of Chemical Engineering, University of South Carolina, Swearingen Engineering Center, Columbia, SC 29208 